\title{
Le site du Bois Hue à Nantes (Loire-Atlantique) et le Second âge du Fer dans l'interfluve Erdre-Loire
}

The settlement of Le Bois Hue in Nantes (Loire-Atlantique) and the Second Iron Age in the Erdre-Loire interfluve

Der Fundplatz von Bois Hue in Nantes (Loire-Atlantique) und die jüngere

Eisenzeit im Zwischenstromgebiet von Erdre und Loire

Axel Levillayer, Valérie Audé, Anne Baron et Emmanuel Mens

\section{OpenEdition}

\section{Journals}

Édition électronique

URL : https://journals.openedition.org/rao/3992

DOI : $10.4000 /$ rao.3992

ISSN : 1775-3732

\section{Éditeur}

Presses universitaires de Rennes

\section{Édition imprimée}

Date de publication : 31 décembre 2017

Pagination : 177-210

ISBN : 978-2-7535-7540-0

ISSN : 0767-709X

\section{Référence électronique}

Axel Levillayer, Valérie Audé, Anne Baron et Emmanuel Mens, « Le site du Bois Hue à Nantes (LoireAtlantique) et le Second âge du Fer dans l'interfluve Erdre-Loire », Revue archéologique de l'Ouest [En ligne], 34 | 2017, mis en ligne le 13 juin 2020, consulté le 23 août 2022. URL : http:// journals.openedition.org/rao/3992 ; DOI : https://doi.org/10.4000/rao.3992 


\title{
Le site du Bois Hue à Nantes (Loire-Atlantique) et le Second âge du Fer dans l'interfluve Erdre-Loire
}

\author{
The Settlement of Le Bois Hue in Nantes (Loire-Atlantique) \\ and the Second Iron Age in the Erdre-Loire Interfluve
}

\author{
Axel Levillayer ${ }^{a}$, Valérie Audé ${ }^{b}$, Anne Baron $^{c}$ et Emmanuel Mens ${ }^{d}$
}

\begin{abstract}
Résumé : La première fouille d'un site gaulois à Nantes met en exergue des caractéristiques particulières, parmi lesquelles une occupation longue entre la fin du IV et le I ${ }^{\text {er }}$ siècle av. n. è., un fossé massif et du mobilier abondant. Son environnement archéologique est tout aussi intéressant, puisque le site du Bois Hue s'inscrit dans un terroir particulier, celui de la confluence de l'Erdre et de la Loire, où les travaux de l'archéologie préventive ont récemment mis en lumière un espace densément occupé à l'âge du Fer. Mise en perspective avec ces découvertes, dont nous chercherons à comprendre les tenants et les aboutissants, la fouille présentée ici permet de dresser un premier bilan de l'occupation gauloise de Nantes.

Abstract: The first excavation of a Gallic settlement in Nantes has revealed that the occupation surrounded by a large ditch lasted for a long period between the end of the $4^{\text {th }}$ and the $1^{\text {st }}$ century B.C. and has provided abundant finds. The archaeological background is very interesting. The settlement of Le Bois Hue is located in a particular context at the confluence of the river Erdre and the Loire, where rescue archaeology has recently revealed a dense occupation dating to the Iron Age. Considering these discoveries, this operation provides a first assessment of Gallic occupation in Nantes.
\end{abstract}

Mots clés : La Tène, enclos d'habitat, réseau de fermes, architectures, céramiques, amphores, jais, meules, échanges commerciaux.

Keywords: La Tène, farmstead, network of farms, architectures, ceramics, amphorae, jet, whetstones, exchange.

L'aménagement de la ZAC Erdre-Porterie à Saint-Joseph de Porterie au nord de Nantes (fig. 1), a conduit, lors d'un diagnostic réalisé par J.-F. Nauleau (INRAP) en 2009, à la découverte d'un site du Second âge du Fer sur les parcelles dites du Bois Hue. La fouille d'une superficie de $7227 \mathrm{~m}^{2}$ a été menée de décembre 2010 à mars 2011. Elle a permis de mettre au jour le premier établissement rural gaulois fouillé à Nantes. Il s'installe sur un coteau dominant l'Erdre et connaît une occupation relativement longue. Le site se présente sous la forme d'un enclos curvilinéaire, étudié dans sa seule partie orientale, caractérisé par un fossé massif dont la stabilité surprend sur toute la durée d'une occupation docu- mentée par un mobilier céramique conséquent. Différents indices permettent de penser que le site jouit d'un statut socio-économique privilégié, au sein d'un terroir fortement mis en valeur à l'âge du Fer entre Erdre et Loire, et qui constitue peut-être l'un des pôles de peuplement principaux de Nantes à la période gauloise.

\section{LE CONTEXTE ENVIRONNEMENTAL}

Le site s'installe sur une éminence schisteuse dominant la vallée de l'Erdre, à environ $500 \mathrm{~m}$ de cet affluent majeur de

\footnotetext{
${ }^{a}$ Grand Patrimoine de Loire-Atlantique, Pôle Archéologie, chercheur associé à l'UMR 6566-CReAAH. (axel.levillayer@loire-atlantique.fr)

${ }^{\mathrm{b}}$ INRAP Grand Sud-Ouest. (valerie.aude@inrap.fr)

' Chercheur associé à l'UMR 5060 IRAMAT - Centre Ernest-Babelon, Orléans. (anne.baron@netcourrier.com)

¿Archéo Atlantica, chercheur associé à l'UMR 5608-TRACES. (emmanuel.mens@free.fr)
} 


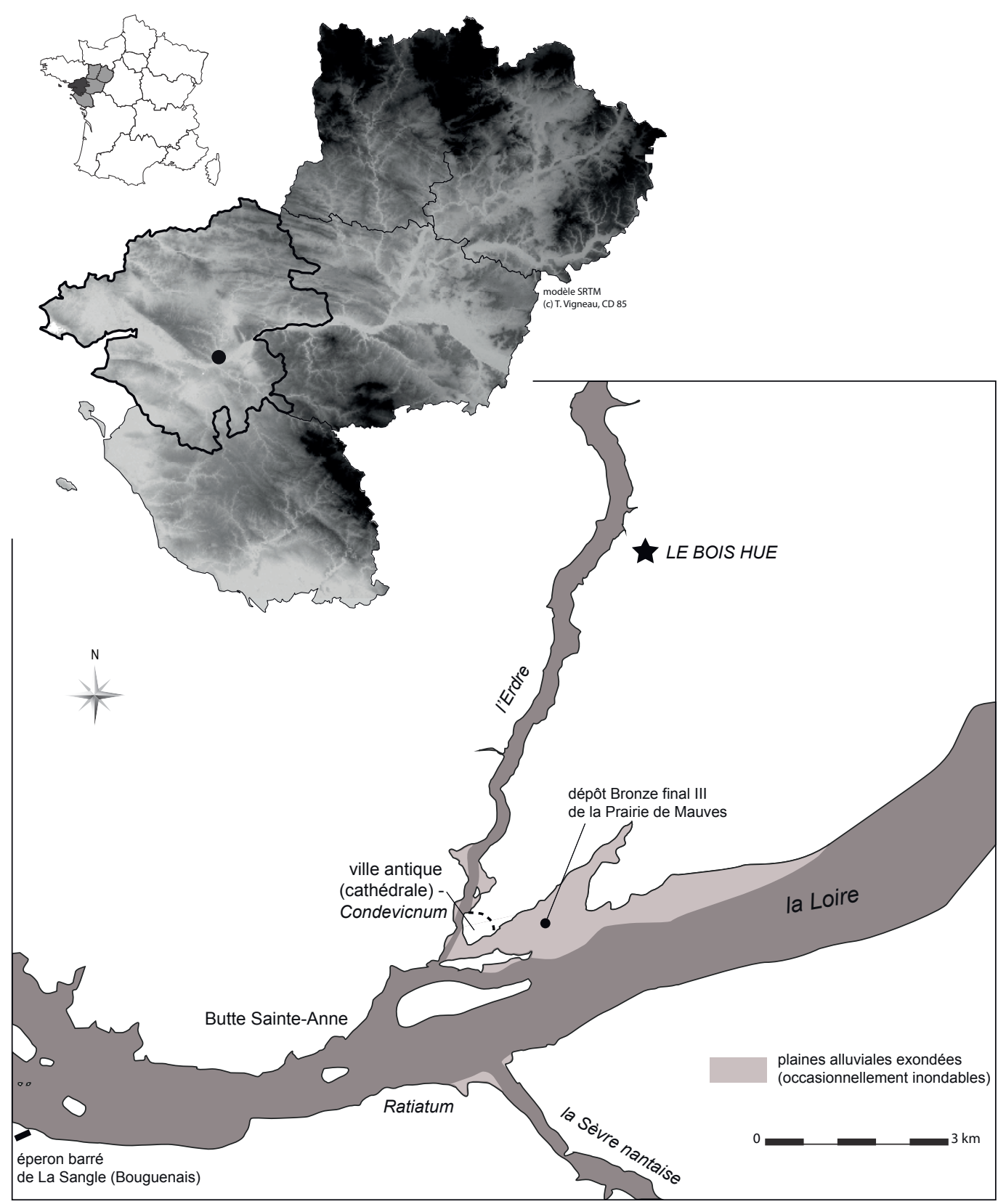

Figure 1 : Localisation du site du Bois Hue à Saint-Joseph de Porterie (Nantes, Loire-Atlantique) dans son cadre régional et au regard de la topographie antique supposée de Nantes (d'apr. Pirault 1996 et N. Lacoste, DParch, Nantes Métropole) (A. Levillayer). Figure 1: Location of Le Bois Hue, Saint-Joseph de Porterie (Nantes, Loire-Atlantique), in its regional context, considering the ancient topography of Nantes.

la Loire (fig. 2). Il est marqué par une pente relativement importante. En effet, il se développe sur le flanc d'un coteau dont la pente orientée sud-sud-ouest présente une déclivité de 4,2\%, à des altitudes comprises entre $25 \mathrm{~m} \mathrm{NGF}$ à l'est et $22 \mathrm{~m}$ NGF, soit 17 à $20 \mathrm{~m}$ au-dessus du niveau d'écoulement de l'Erdre. Le site domine un thalweg où un petit bassin de rétention des eaux a d'ailleurs été aménagé dans le parc du château moderne installé sur le site. Ces aménagements subcontemporains ont " bloqué " les colluvions qui ont recouvert le site, avec parfois une puissance importante (jusqu'à 1,2 $\mathrm{m}$ d'épaisseur). Cette sédimentation très humique s'est produite bien après l'abandon du site gaulois, puisqu'aucun niveau de sol n'a été retrouvé. Toutefois, elle a préservé les parties basses du site des destructions modernes ou contemporaines liées aux pratiques de maraîchage qui ont marqué ce secteur de Nantes au $\mathrm{xx}^{\mathrm{e}}$ siècle, et qui ont profondément bouleversé les vestiges archéologiques de la moitié nord du site.

\section{Plan et organisation du site du Bois Hue}

\section{Un fossé d'enclos remarquable}

Le fossé d'enclos (numéroté F 545/546) a été suivi sur un peu plus de $145 \mathrm{~m}$. Il adopte un tracé globalement curvi- 


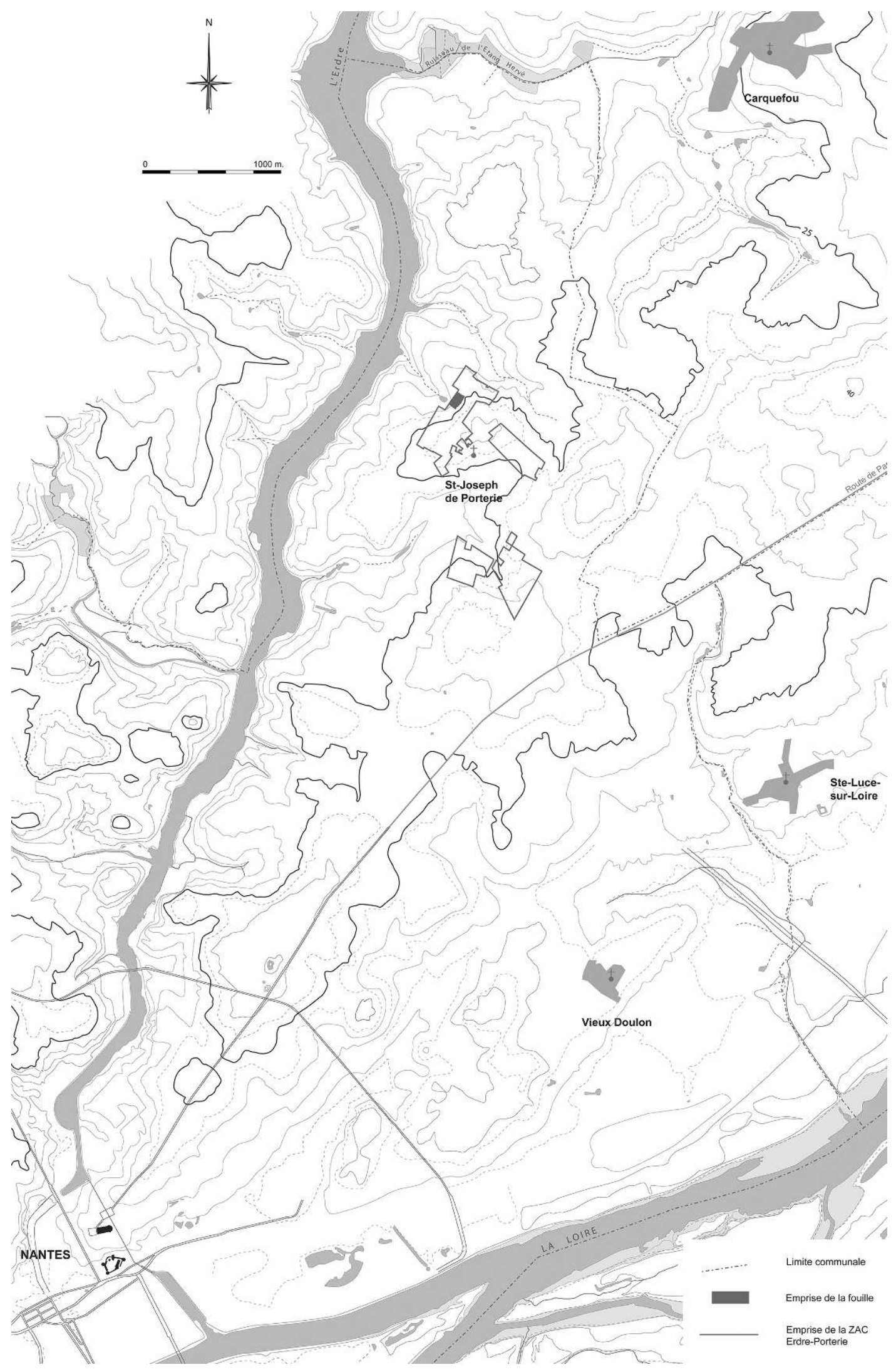

Figure 2 : Contexte topographique du site (E. Boutonnet).

Figure 2: Topographical context of the settlement. 
linéaire (fig. 3). Dans la partie sud de l'emprise, il dessine une cour appréhendée sur une largeur maximale de $43 \mathrm{~m}$. Suivant une orientation nord-ouest/sud-est dans sa partie méridionale, puis sud-ouest/nord-est, il oblique brusquement vers le nord. L'ensemble de l'enclos n'a pas été dégagé. Au sud, le fossé se prolonge vers le nord-ouest, sous les terrains de l'actuel château, sans qu'on ait noté d'inflexion dans son tracé. Lors de cette fouille, aucun retour au nord n'a été appréhendé. La superficie enclose fouillée se monte à $3505 \mathrm{~m}^{2}$.
La réalisation d'une fouille complémentaire en 2013, sous la direction de S. Munos (2014), sur une superficie restreinte $\left(1700 \mathrm{~m}^{2}\right)$, a permis de reconnaitre le retour $\mathrm{du}$ fossé à l'ouest de la fouille qui fait l'objet du présent article, ainsi qu'un fossé secondaire.

Le fossé 545/546 mesure entre 2,3 m et 3,6 m de largeur à l'ouverture (fig. 4). Les plus importantes largeurs sont atteintes dans la partie occidentale où il dépasse systématiquement 2,9 m. La moyenne générale sur les $150 \mathrm{~m}$ linéaires étudiés est de 2,86 m. Les profondeurs varient également

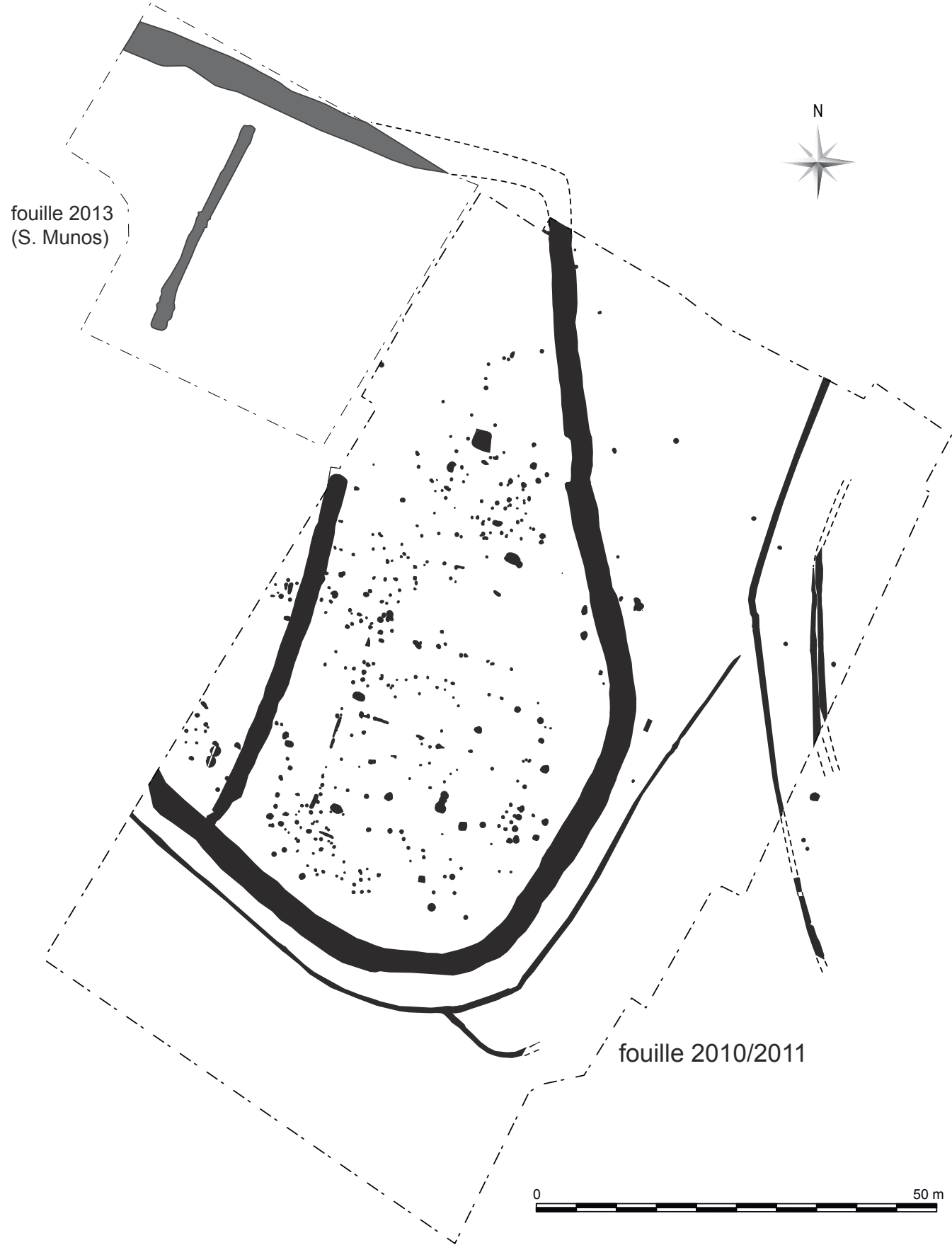

Figure 3 : Plan général du site (seules les structures de l'âge du Fer ont été représentées) complété par celui de la fouille de 2013 (A. Levillayer; Munos, 2014).

Figure 3: General plan of the excavation (representing only the Iron Age structures). 
entre $1,4 \mathrm{~m}$ au nord et $2 \mathrm{~m}$ au sud, sous le niveau d'apparition des structures (si on ne tient pas compte de l'entrée où le fossé n'est profond que de 0,6 m).

Le terrain présente une forte déclivité N/S. L'étude des altitudes de fonds de fossé est des plus intéressantes. En effet, celles-ci sont sensiblement identiques depuis l'angle sud-est de l'enclos jusqu'à son extrémité nord. Au nord de l'entrée, elle oscille entre 20,7 m NGF et 20,8 m NGF, et au sud de celle-ci, entre 20,6 m NGF et 21,1 m NGF. Aucune pente significative ne peut ainsi être mise en évidence. Il en va tout autrement pour la partie sud de l'enclos. En effet, la façade méridionale est marquée par une forte pente, avec une différence de près de $2,5 \mathrm{~m}$ entre la partie haute $(20,75 \mathrm{~m} \mathrm{NGF})$ et la partie basse (18,39 m NGF). À l'inverse donc de la façade orientale, le fossé suit la pente naturelle, l'accentuant même légèrement, dans sa partie sud.

Cette rupture dans la conception même du fossé, rupture située à l'angle sud-est de l'enclos, correspond à un changement dans le profil du fossé. En effet, de manière schématique, le fossé $545 / 546$ présente un profil en $\mathrm{V}$ à bords nets qui dénotent un soin particulier apporté au creusement alors qu'il est majoritairement réalisé dans des roches schisteuses dures et très foliées (fig. 5). Ce profil évolue vers un profil en $\mathrm{V}$ tronqué à fond aplani, profil qu'on retrouve presque systématiquement dans la partie est du fossé. À l'inverse, à l'exception du sondage 30 , le fossé $545 / 546$ adopte un même profil triangulaire sur la façade sud. Cette configuration pourrait résulter de la nécessité de curages plus fréquents dans la partie orientale, précisément là où le fossé est nivelé. Sur la façade méridionale en revanche, les interventions, au moins dans les premières phases, étaient moins nécessaires du fait de la pente.

Une entrée a été mise en évidence dans la partie nord de la façade orientale. Cette entrée se présente sous la forme d'un rétrécissement du fossé d'enclos, en largeur d'une part $(1,4 \mathrm{~m})$, et en profondeur d'autre part puisque, sur près de $3 \mathrm{~m}$, le fossé est seulement profond de 0,5 à $0,8 \mathrm{~m}$ et adopte un profil en auge (fig. 6). Elle se marque également par un léger décrochement du tracé du fossé vers l'est, qui dessine à cet endroit une légère courbure. Ce type d'entrée nécessite un franchissement aérien du fossé, dont aucune trace d'ancrage au sol n'a été retrouvée. Bien plus rare que les simples interruptions du fossé d'enclos, ce système se rencontre parfois à l'âge du Fer, et résulte manifestement de la nécessité de ne pas bloquer la circulation de l'eau et « éviter [ainsi] le déversement des eaux accumulées dans le fossé " au niveau de l'entrée (Menez, 2008, p. 433). À Nantes, cette configuration permet aussi que les eaux provenant du haut du plateau ne ruissellent directement à l'intérieur de l'enclos.

Malgré une fouille fine, il n'a pas été possible de déterminer si l'aménagement de cette entrée était contemporain du creusement du fossé. C'est probable, mais on peut tout autant envisager que la nécessité de laisser l'eau circuler ne se soit imposée qu'au fur et à mesure du fonctionnement du fossé d'enclos, peut-être alors que celui-ci se comblait progressivement et que ce creusement témoigne d'une seconde phase d'aménagement. L'absence de mobilier ancien dans les phases de comblement ne constitue pas un argument de sa postériorité, dans la mesure où, déjà peu profonde, cette entrée devait être régulièrement nettoyée et se comblait moins rapidement que le reste du fossé, l'eau n'y circulant que rarement. Reste que la profondeur du fossé au niveau de cette entrée correspond plus ou moins à la puissance de l'US supérieure du fossé qui marque l'abandon du site.

L'analyse des comblements des différentes parties du fossé met en lumière une stratigraphie homogène lato sensu. Au-delà de quelques épiphénomènes, l'homogénéité des séquences de sédimentation que confirment les coupes longitudinales, permettent d'identifier trois principales séquences (fig. 7).

Toutes les données attestent un fonctionnement ouvert du fossé. La provenance du mobilier est stratigraphiquement homogène, issu pour partie du comblement inférieur, mais principalement des niveaux de surface qui correspondent à l'abandon du site. À l'inverse les niveaux intermédiaires sont pauvres en matériel.

La séquence basale est caractérisée par des couches argileuses grises hydromorphes qui témoignent d'une stagnation de l'eau dans laquelle les sédiments argileux fins en suspension se déposent au fond (fig. 7, US 2). L'association de ces argiles à des éléments proches du substrat (schiste et argiles jaunes faiblement limoneuses) trahit une première érosion des parois comme c'est généralement le cas dans les premières phases de comblement d'un fossé ouvert. Au Bois Hue, ce niveau observable sur l'ensemble du tracé du fossé, est associé à un mobilier ancien et homogène.

La séquence suivante est davantage sujette à des variations ponctuelles, notamment par la latéralisation des apports à certains endroits qui peuvent avoir des causes multiples (présence d'un talus, phénomène érosif...). Elle se caractérise par des dépôts limoneux souvent puissants, qui livrent peu de mobilier (fig. 7, US 3 à 5). Cette pauvreté s'explique en partie par des nettoyages successifs constatés à diverses reprises sous la forme de curages. Le faciès sédimentaire de limons argileux, souvent graveleux, trahit la provenance des comblements issus majoritairement du lessivage des sols. L'hydromorphie ne semble pas jouer un rôle majeur dans la différenciation des stratigraphies. La sédimentation est plus lente qu’à la phase précédente.

La dernière séquence concerne bien souvent un niveau unique qui correspond au comblement terminal du fossé (fig. 7, US 6 à 9). Relativement proche d'un point de vue 


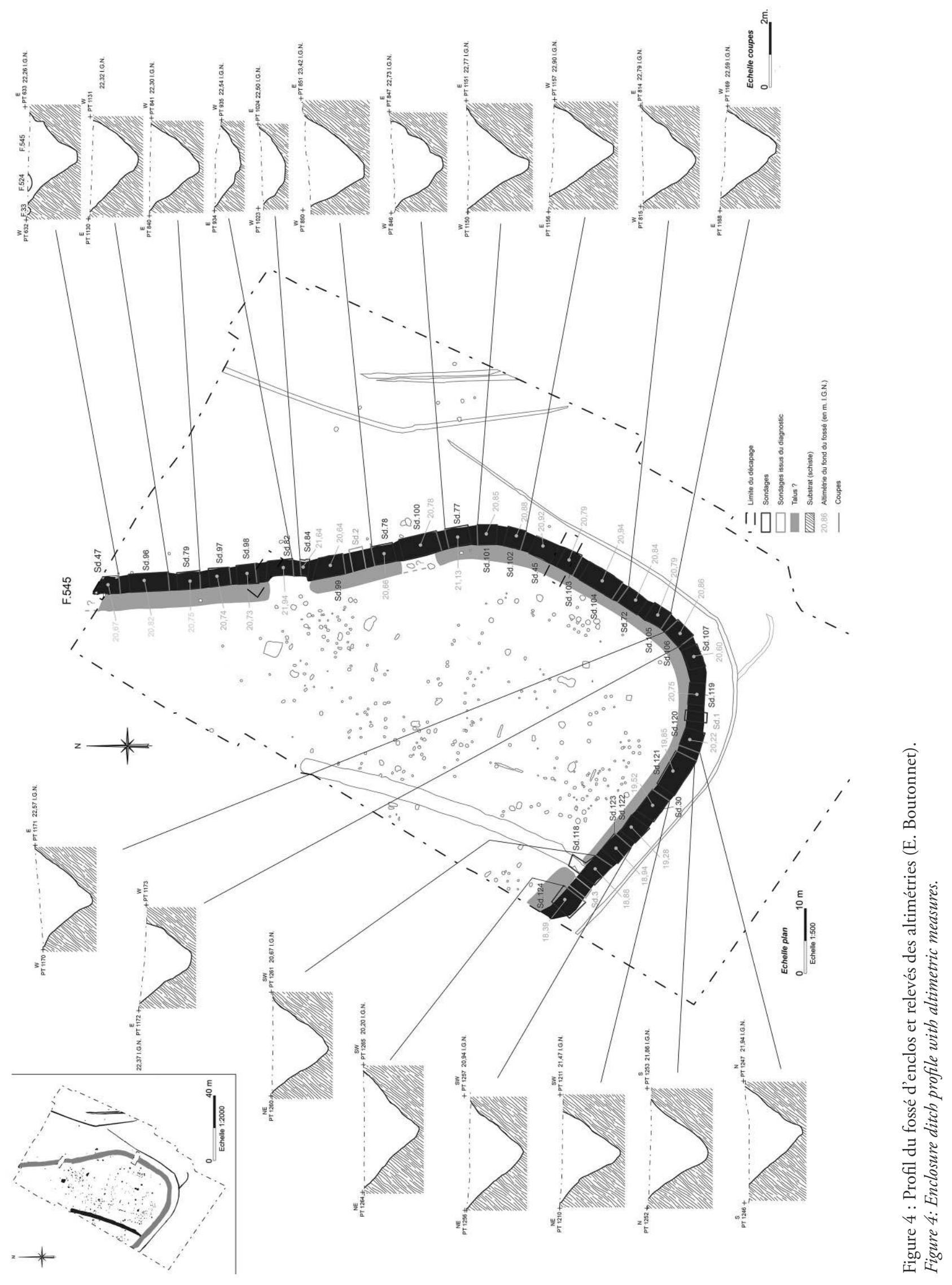




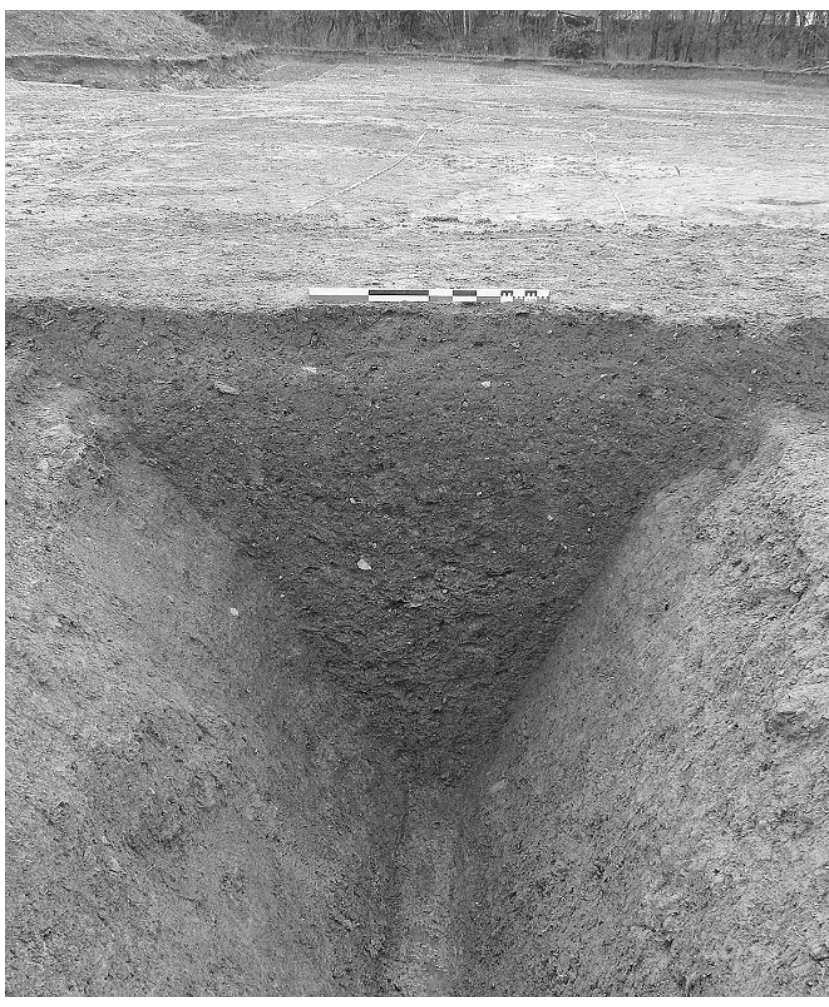

Figure 5 : Vue en coupe du fossé d'enclos (A. Levillayer). Figure 5: View of an enclosure ditch section.

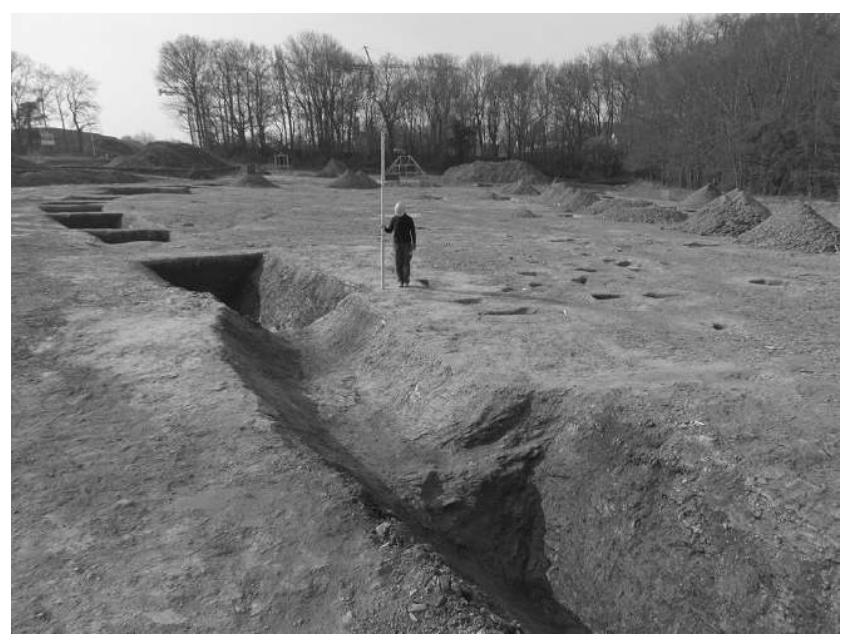

Figure 6 : Vue de l'entrée de l'enclos (A. Levillayer).

Figure 6: View of the entrance to the enclosure.

sédimentaire des niveaux sous-jacents, cette séquence se caractérise par l'abondance des rejets anthropiques qui marquent l'ultime phase de comblement du fossé. Le profil de ces niveaux à certains endroits du fossé (comme celui représenté ici) pourrait suggérer qu'il ait fait l'objet de recreusements ponctuels.

L'existence d'un talus interne semble attestée par la présence de nombreux apports latéralisés de nature graveleuse à l'inverse du sens de la pente, dont l'aspect est proche du

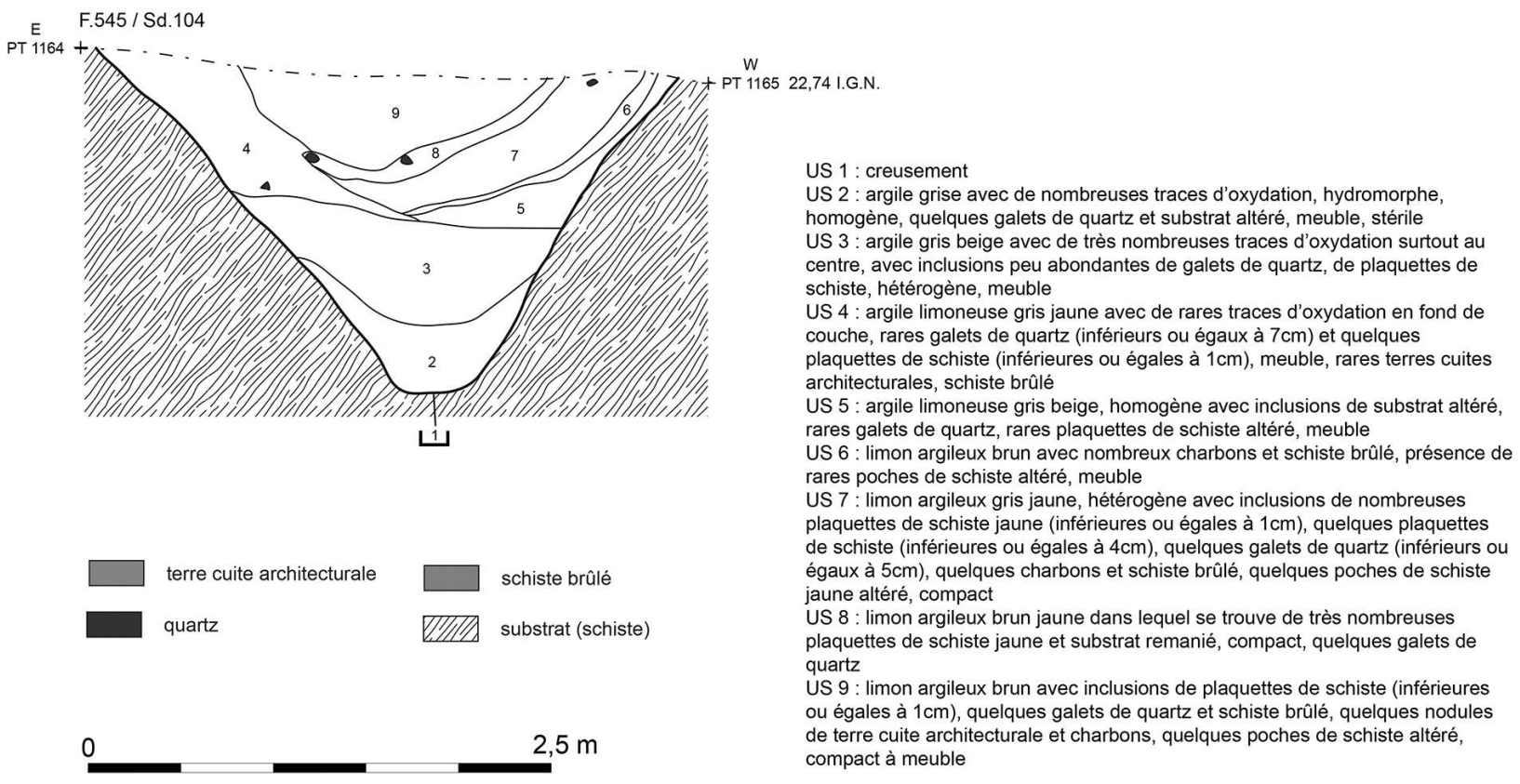

Figure 7 : Exemple de coupe du fossé d'enclos (F 545, sd 103) (A. Levillayer).

Figure 7: One of sections of enclosure ditch (F 545, sd 103). 
substrat (matériau probablement issu du creusement du fossé). Des blocs de schiste découverts dans le sondage 47 , toute prudence gardée, pourraient participer, sinon d'un parement, du moins de l'édification du talus, dont l'existence est également attestée par l'absence presque systématique de vestiges sur une bande de 2 à $3 \mathrm{~m}$ de largeur en arrière du fossé.

La question du rôle de drainage du fossé se pose également. L'appréciation de son impact ne peut toutefois pas être réellement mesurée. Le fossé, on l'a dit, est en partie installé autour d'une éminence schisteuse qu'il ceinture de façon approximative. Au sud, il est aménagé dans les argiles sus-jacentes, ne perforant le schiste qu'en partie basse. Lors de son ouverture, en hiver, le fossé méridional, orienté dans le sens de la pente, jouait toujours un rôle drainant. Sur la façade orientale de l'enclos en revanche, aucune pente n'a été aménagée dans un secteur qui constitue pourtant le point haut du site, localisé en milieu de coteau. L'hydromorphie atteste toutefois bien d'une présence d'eau qui, de façon sans doute très ponctuelle, pourrait avoir été importante.

\section{L'organisation interne du site}

\section{Un fossé de partition}

Le fossé F 547 a pu être suivi dans sa totalité, depuis sa jonction avec le fossé d'enclos au sud, jusqu'à son interruption au nord, soit sur une longueur de $45 \mathrm{~m}$ (fig. 8). Ce fossé d'orientation SO-NNE au tracé légèrement curviligne, partitionne l'enclos dans sa partie méridionale. Il s'interrompt en vis-à-vis de l'entrée repérée dans le fossé d'enclos, confirmant l'importance structurelle de celle-ci.

Le fossé adopte des dimensions relativement régulières (fig. 9). Il mesure en moyenne 2,2 $\mathrm{m}$ de largeur à l'ouverture, si l'on excepte un rétrécissement notable au niveau de sa jonction avec le fossé d'enclos. La question peut alors être posée de savoir si ce rétrécissement et le tracé irrégulier qui l'accompagne, témoignent d'un fossé d'abord interrompu, qui aurait été rallongé par la suite, afin qu'il communique avec le fossé $545 / 546$, ceci pour gérer d'éventuels problèmes d'eau. Toutefois, aucune trace de recreusement n'a été perçue à la fouille, ni en plan, ni en coupe. La profondeur du fossé varie de $0,7 \mathrm{~m}$ au sud, à l'endroit de sa jonction avec F 545/546, à 1,3 m dans le sondage 95. Le fossé va ainsi en s'agrandissant, tant en largeur qu'en profondeur à proximité de son interruption, comme c'est souvent le cas sur de nombreux sites de l'âge du Fer à proximité des accès (Maguer, 2000 , p. 20). Sa profondeur moyenne est de l'ordre de $0,9 \mathrm{~m}$, avec un nivellement relativement régulier. Il n'a pas été nécessaire d'aménager une pente forte pour ce fossé qui devait pourtant drainer les eaux ruisselant depuis la partie est de l'enclos. Le creusement du fossé adopte un profil en auge à fond incurvé ou légèrement aplani. Certaines parois sont parfois très évasées. Ces profils pourraient résulter, comme pour le fossé d'enclos, de curages du fossé qui accélèrent l'érosion des parois.

Ces nettoyages sont difficiles à percevoir, dans une stratigraphie peu lisible, du fait notamment de conditions de fouille particulièrement pénibles dans ce secteur localisé en contrebas du site, avec un ennoyage continu des sondages. La stratigraphie générale est toutefois relativement homogène. Elle consiste en trois à quatre niveaux de comblement déposés selon un profil d'équilibre relativement régulier. La coupe pratiquée à l'intersection des deux fossés ne permet pas, en raison de la trop grande différence de niveaux entre les deux fossés, d'attester de la contemporanéité de leur creusement. Cependant le mobilier semble démontrer que le fossé de partition existait dès la fondation du site.

\section{Les bâtiments}

Sur les 366 faits archéologiques enregistrés, on recense 313 trous de poteau. Une grande majorité d'entre eux sont de simples creusements à profil en cuvette comblés par des limons argileux, dont le compactage des sédiments - issus du creusement du trou de poteau - assure la stabilité du poteau, méthode d'autant plus efficace au regard de la nature argileuse du sous-sol.

La densité des trous de poteau à l'intérieur de l'enclos est donc importante. Résultant de la longue durée d'occupation, elle témoigne d'aménagements successifs mais nuit fortement à la lecture de plans de bâtiments. Vingt bâtiments ont cependant pu être mis en évidence, qui montrent une certaine diversité architecturale (fig. 10). Bien que les restitutions, eu égard à la densité, doivent être considérées avec prudence, trois (voire quatre) groupes ont été constitués, qui prennent en compte à la fois la superficie et la morphologie, laquelle inclue le nombre de poteaux porteurs. La superficie est calculée à partir du module porteur. La surface réelle du bâtiment peut donc avoir été plus importante.

Six bâtiments entrent dans la catégorie des "greniers " qui correspond à des édifices principalement édifiés sur quatre poteaux porteurs, de plan grossièrement quadrangulaire, et dont les superficies varient entre 1,50 et $6 \mathrm{~m}^{2}$. L'écartement entre les poteaux est de l'ordre de 2 à $3 \mathrm{~m}$. Ce type de construction est généralement interprété comme des greniers surélevés mais peut correspondre à bien d'autres usages (Maguer, 2000, p. 69). Ces six constructions qui correspondent aux architectures de stockage majoritaires à l'âge du Fer dans l'Ouest (Bossard et al., à paraître), présentent la caractéristique d'être à deux reprises associées par deux (E1-E2 et E4-E5), et de se situer dans la partie sud-est de l'enclos. 


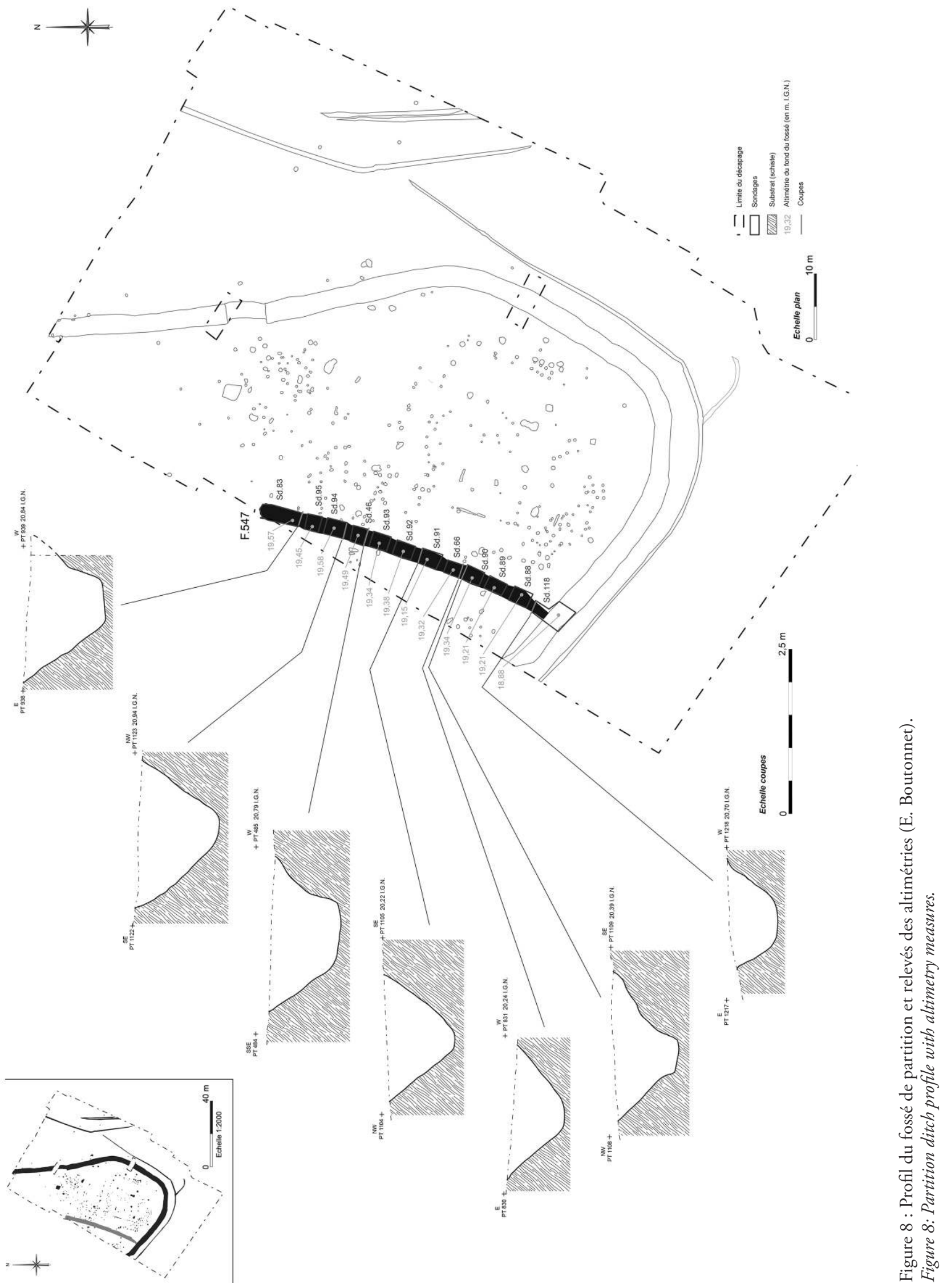




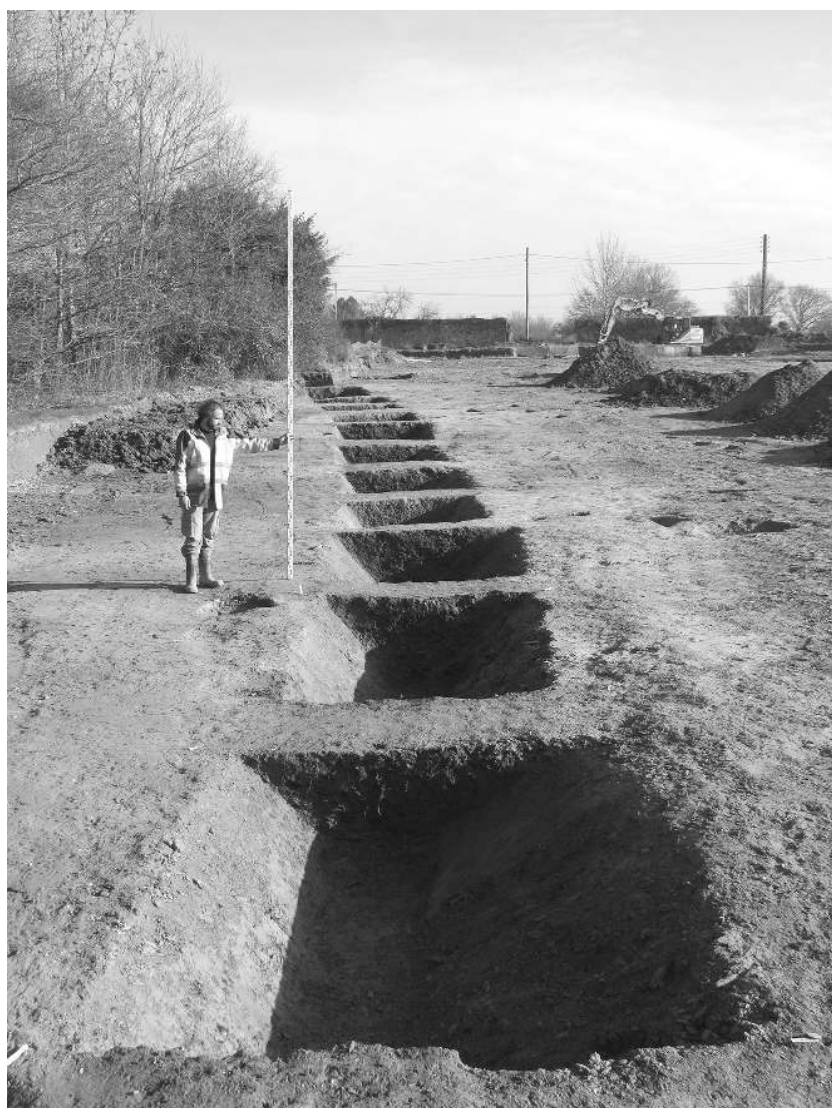

Figure 9 : Vue générale du fossé de partition en cours de fouille (A. Levillayer).

Figure 9: General view of the partition ditch during excavation.

Le deuxième groupe rassemble six (voire sept) bâtiments dont la fonction est essentiellement déduite à partir de leurs surfaces : il s'agit des " annexes». Deux types de plans se distinguent : les plans rectangulaires (bâtiments E7, E8, E9 et E10) et les plans à angles coupés (E11, E12 et E 13 ?). Les premiers dessinent des plans de 5 à $12 \mathrm{~m}^{2}$ au sol. Les ensembles E11 et E12 pourraient former une sous-catégorie. À partir de l'ensemble E11, nous avons restitué une architecture à angle coupé, plan bien connu, par exemple à AcyRomance, où ils constituent un module type de l'habitat et de ses annexes (Lambot, 2002). La superficie, de l'ordre de $12 \mathrm{~m}^{2}$, correspond également à ce qui peut être rencontré. Un temps nous avons associé ce bâtiment à un plan à parois rejetées - à l'image de constructions déterminées par P. Maguer (2005) - mais cette hypothèse, du fait de la modestie du module porteur et de sa proximité avec ce qui constituerait l'emplacement de la paroi, a été écartée. De surcroît, le plan de bâtiment rectangulaire à un seul pignon à angles coupés, s'accorde tout à fait avec la présence, sur le côté rectiligne, d'un poteau central (F 436). Le TP 423 livre une écuelle attribuable à la fin de La Tène $\mathrm{C}$ ou à La Tène D1. L'ensemble E12 n'a été identifié qu'après la restitution de l'ensemble précédent avec qui il partage plusieurs caractéristiques, dont la surface (11,50 $\mathrm{m}^{2}$ en ce cas). Toutefois, la façade sud-ouest pourrait davantage être assimilée à une abside (Buchsenschutz, 2005, fig. 5). L'unicité de l'abside est surprenante mais aucune structure ne semble lui faire pendant au nord-ouest. L'ensemble E13 pose les mêmes questions, surtout au regard de sa localisation au cœur d'une zone dense en creusements située juste en arrière de l'entrée. Sans qu'on puisse écarter que les poteaux de cet ensemble participent en fait d'un système lié à l'entrée elle-même (porte-porche?), nous évoquons ici la possibilité d'un autre bâtiment de dimensions plus importantes $\left(18 \mathrm{~m}^{2}\right)$, formé par des poteaux de modules conséquents, et au sein duquel on note la présence d'une fosse riche en céramiques et en terres cuites.

Ces différents bâtiments, s'ils peuvent revêtir des réalités, architecturales notamment, différentes, peuvent être identifiés à des édifices liés à l'exploitation agricole (remises à outils, bergerie, etc.) ou, ainsi que pourrait le suggérer la présence de grandes fosses dans trois d'entre eux (E7, E10 et E13), à un artisanat ponctuel.

Un groupe de huit bâtiments, d'architecture et de plans variés, a été défini à partir de leurs superficies qui oscillent entre 20 et $30 \mathrm{~m}^{2}$. Ces bâtiments peuvent correspondre à des habitations (Maguer, 2000, p. 74) mais peuvent tout aussi bien à nouveau avoir servi d'annexes agricoles (grange, écurie, etc.). Les ensembles E14, E15 et E16 se caractérisent par des plans rectangulaires à une nef. Leur superficie est assez modeste pour ne pas nécessiter de travées multiples : $20 \mathrm{~m}^{2}$ pour E16, 24,50 $\mathrm{m}^{2}$ au minimum pour E14, et $33 \mathrm{~m}^{2}$ pour E15. L'ensemble E17, d'une surface de $25 \mathrm{~m}^{2}$, est un unicum à l'échelle du site mais relève d'un type courant en Europe celtique, identifié comme des bâtiments à deux nefs à pignon (Buchsenschutz, 2005, fig. 6; Dechezleprêtre et al., 2000, fig. 4). Les quatre poteaux porteurs ont des diamètres et des profondeurs relativement importantes (entre 0,4 et $0,5 \mathrm{~m}$ de diamètre), un négatif conservé montrant un poteau de $0,3 \mathrm{~m}$ de section. Un bâtiment de plan proche, qui mesure exactement le double de celui du Bois Hue, a été découvert sur le site de la Chapellière à la Chaize-leVicomte en Vendée (Maguer et al., 2005). L'exemple découvert ici présente deux poteaux faîtiers. Ceux-ci présentent un ancrage au sol moins important que les poteaux d'angle et sont désaxés par rapport au plan tracé par les quatre autres creusements, ce qui plaide pour l'existence de pignons.

Le dernier ensemble, E 18, est très hypothétique. Il témoigne en fait d'un ensemble de structures situées au sud du bâtiment E12, autour et au sein desquelles du mobilier a été découvert. Ces creusements forment un arc de cercle grossier qui pourrait à nouveau être interprété comme un angle coupé. Cette interprétation pose toutefois souci dans 


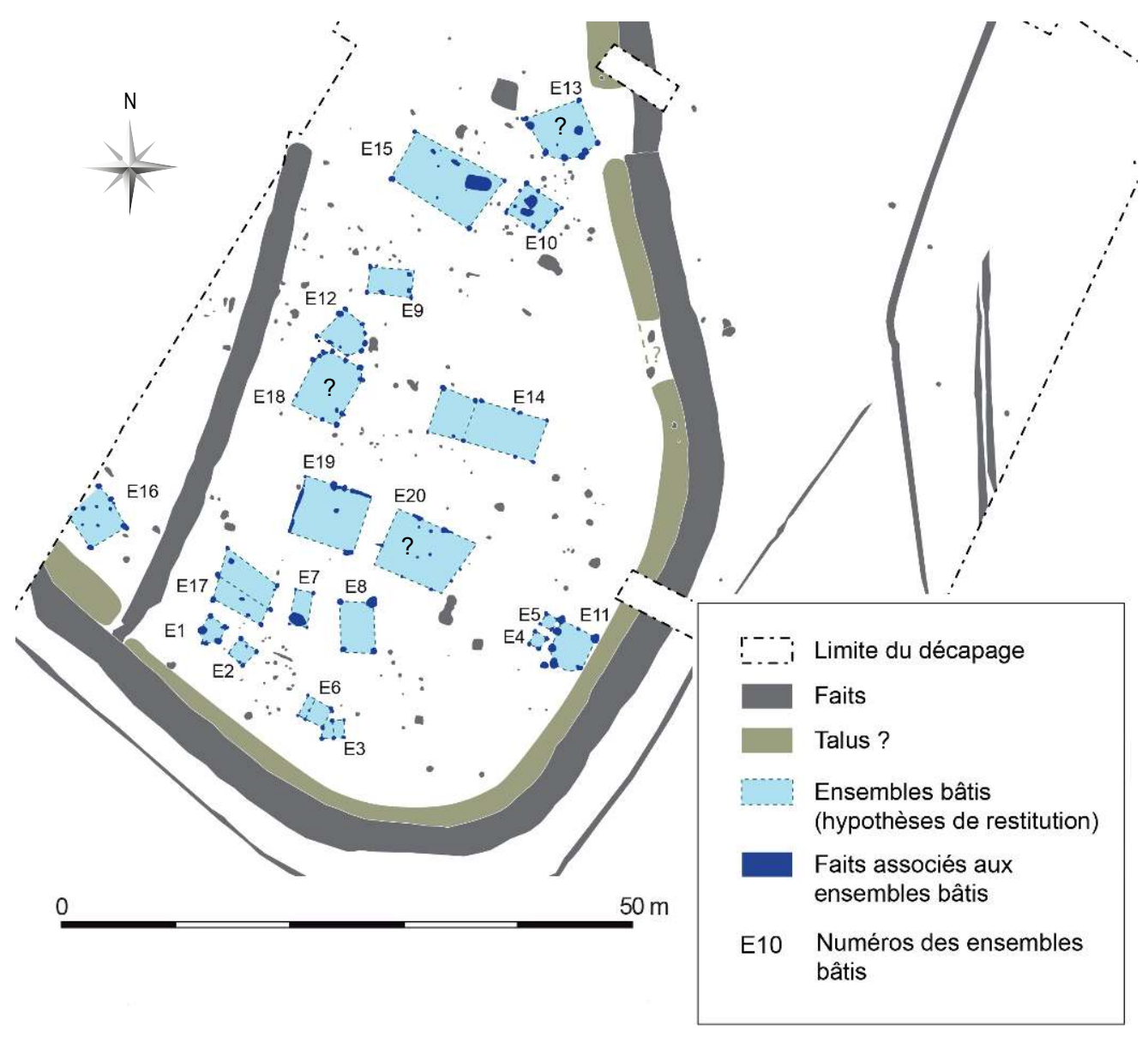

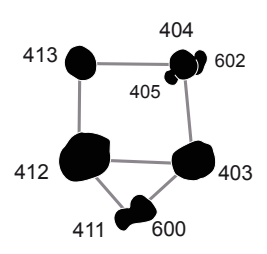

E 1

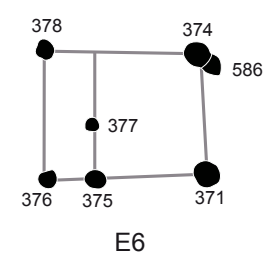

E6

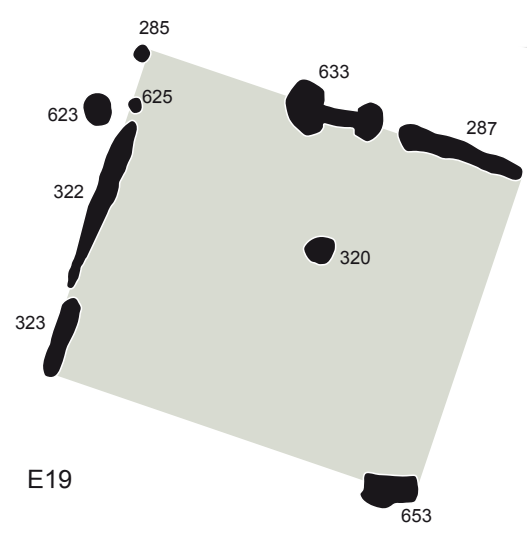

0

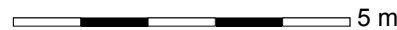

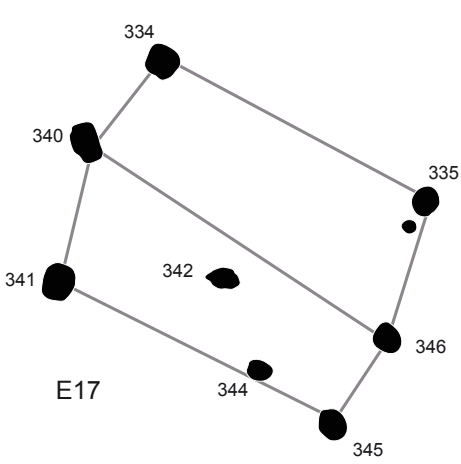

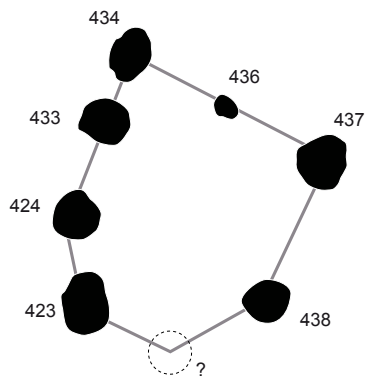

E11

Figure 10 : Plan général des architectures du site et plans détaillés de quelques bâtiments (A. Levillayer).

Figure 10: General plan of the architectures and detail plans of some of the buildings. 
la mesure où, au sud-est, les faits qui pourraient relever de ce bâtiment sont rares. Sa superficie serait d'un peu plus de $23 \mathrm{~m}^{2}$.

Dans la moitié sud du site, bordant un espace relativement vierge de toute structure, un bâtiment à l'architecture différente a été mis en évidence, par la présence de tranchées de fondation (probablement de longrines) et d'un seuil, l'ensemble E19. Les tranchées conservées à l'ouest et au nord se présentent comme des creusements larges de 0,3 à $0,4 \mathrm{~m}$ de largeur. Conservée sur une vingtaine de centimètres de profondeur, la tranchée Nord mesure $2 \mathrm{~m}$ de longueur. Les tranchées occidentales ont eu à subir deux décapages successifs puisqu'elles avaient été découvertes lors du diagnostic. Ainsi, il n'est pas impossible qu'il s'agisse d'une seule et même tranchée qui atteindrait alors $4 \mathrm{~m}$. Dans un sondage, on perçoit des surcreusements à profil en cuvette d'une vingtaine de centimètres de diamètre qui pourraient correspondre à des emplacements de poteaux. Au sud-est, une " fosse » étroite de plan quadrangulaire pourrait constituer le vestige d'une autre tranchée de fondation qui, dans sa partie occidentale, présente également un surcreusement. Si l'on tient compte de l'extrémité de ces tranchées, parfaitement perpendiculaires entre elles, on en arrive à un module carré de $5 \mathrm{~m}$ de côté. Au centre de la façade nord, un ensemble de deux trous de poteaux de 0,62 et $0,90 \mathrm{~m}$ de diamètre (pour des profondeurs de 0,19 et $0,20 \mathrm{~m}$ ), sont reliés par une tranchée de $0,43 \mathrm{~m}$ de longueur pour $0,23 \mathrm{~m}$ de largeur. Cet aménagement, tant dans sa morphologie que dans son emplacement, présente les caractéristiques d'une tranchée de seuil marquant l'entrée principale du bâtiment (Maguer, 2000, p. 91). Ce type de bâtiments est de plus en plus fréquemment identifié sur les sites de la région (Maguer et Robert, 2013), l'association entre tranchées de fondation et poteaux porteurs ayant par exemple, en Loire-Atlantique, été mise en lumière à Ancenis (Pétorin, 2009, fig. 34).

Délimité par trois paires de trous de poteau - dont certains présentent un plan "en trou de serrure " - un ensemble nommé E20 s'aligne parfaitement sur le précédent, à la fois au nord et au sud. Ainsi, bien qu'aucun plan ne puisse être restitué, il nous semble plausible d'associer ces creusements. La superficie couverte est de $34,30 \mathrm{~m}^{2}$. Au vu de l'architecture du bâtiment E19 dont aucune trace ne subsiste à l'est, on peut avancer l'hypothèse que l'ensemble E20 ait également été érigé sur tranchée de fondation, les poteaux marquant des entrées. La dimension des structures en « trou de serrure " est importante (1,30 m et 1,14 $\mathrm{m}$ de longueur) pour des poteaux dont le trou proprement dit atteint $0,5 \mathrm{~m}$.

Au terme de cette étude, et si nombre d'ensembles bâtis doivent être considérés avec prudence, il n'en reste pas moins que l'ensemble des types de bâtiments qu'on rencontre sur un site à vocation agro-pastorale de l'âge du Fer est repré- senté. L'identification (qui reste hypothétique), à côté des plans rectangulaires simples à une ou deux nefs, de bâtiments à pignon à angles coupés est relativement originale pour la région et témoigne, sur la durée de l'occupation, d'architectures variées (en témoignent également la variété des modes de conception qui associe architectures sur poteaux et sur tranchées de fondation).

\section{Les autres structures}

Quarante-six fosses sont attribuables à l'occupation de l'âge du Fer, mais seize seulement ont livré du mobilier. Aucun aménagement particulier n’y est associé.

Plusieurs remarques concernant l'organisation générale peuvent être faites. La première est le rôle de l'entrée dégagée à l'est du site, et qui paraît constituer l'entrée principale (ou l'une des entrées principales) du site. En effet, le fossé de partition s'interrompt exactement dans l'alignement de cette entrée. On constate d'ailleurs qu'au niveau de son interruption, F 547 s'élargit, suivant un phénomène largement répandu à proximité des entrées principales (Maguer, 2000, p. $20 ;$ Menez, 2008, p. 46). Si l'on excepte l'ensemble E13, il y a très peu de structures dans cet axe. L'entrée, dont on a déjà noté le soin qui y a été apporté, mesure près de $3 \mathrm{~m}$ de largeur, ce qui en fait une entrée structurante, permettant notamment l'accès aux charrettes et véhicules tractés. Est-ce l'entrée principale du site? C'est possible, mais on signalera qu'aucune structure n'y est associée, qui formerait un aménagement remarquable (porche...). On notera enfin avec intérêt que cette entrée se situe en vis-à-vis de l'inflexion du chemin protohistorique descendant du plateau (cf. infra).

Le fossé de partition fonctionne dès l'occupation initiale du site. Son rôle est délicat à définir du fait de sa situation en limite de fouille. Ainsi, il est impossible de savoir si la plus faible densité de vestiges qui pourrait caractériser son côté ouest est une réalité ou si notre vision est biaisée par le faible espace étudié. Notons toutefois que ce fossé concentre des mobiliers artisanaux (scories de fer et de bronze) et des meules, ce qui laisserait penser que les activités vivrières pouvaient s'organiser autour de lui, voire que la partie ouest du site pourrait avoir servi «d'avant-cour » non domestique.

Malgré les nombreuses restructurations visibles à l'intérieur du site, mettant encore plus en exergue la pérennité $\mathrm{du}$ fossé d'enclos, des espaces vides ou moins densément bâtis, sont discernables. C'est le cas dans l'angle sud-ouest du site, au nord des grands ensembles E19 et 20, et entre les bâtiments E9, E10 et E14. Il n'est en revanche pas possible de savoir si l'absence de vestiges gaulois au nord du site reflète une réalité archéologique ou est due à leur destruction par les vestiges subcontemporains liés au maraîchage. Les espaces vides peuvent correspondre à des réalités et à des usages différents. Il peut notamment s'agir de cours dédiées 
à diverses activités agricoles ou domestiques. Dans le cas de l'espace qui enserre les ensembles E19 et E20 (parmi les plus vastes du site) on pourrait y voir la zone périphérique de bâtiments d'habitation.

On observe également la concentration de bâtiments de type " greniers " en deux points du site, dans sa partie méridionale. En revanche, nous ne pouvons que constater l'absence de structures de combustion, dont la disparition découle de celle des niveaux de sol.

\section{Les espaces périphériques : un chemin gaulois et des incinérations antiques}

À l'est du site, un ensemble de trois fossés présente toutes les caractéristiques d'un chemin (fig. 11). Le fossé 535, le plus à l'ouest, descend du plateau suivant une orientation SSE-NNO, et adopte un tracé rectiligne parallèle à celui de la partie nord du fossé d'enclos sur $26 \mathrm{~m}$. Puis, le fossé oblique vers le NE et se prolonge au-delà la limite de fouille. Outre son tracé régulier, ce fossé (malheureusement perturbé par un fossé moderne) adopte un profil en auge à fond incurvé relativement régulier, large de 0,6 m et profond de $0,3 \mathrm{~m}$. Le comblement du fossé est remarquablement homogène d'un bout à l'autre de son tracé. Il s'agit d'un sédiment argilo-limoneux brun clair très compact, mêlé de graviers de schiste.

Parallèle à F 535, le fossé 538 n'est plus visible au nord de son intersection avec un large fossé moderne, soit qu'il n'a jamais existé, soit plus probablement qu'il a été détruit par celui-ci. En effet, outre son tracé, ses caractéristiques sont très proches de celles de $\mathrm{F} 535$ : présentant un profil en auge, il atteint au maximum $0,70 \mathrm{~m}$ de largeur pour une moyenne située entre 0,46 et $0,54 \mathrm{~m}$, le fossé allant en se rétrécissant vers le nord. La profondeur varie également de $0,15 \mathrm{~m}$ à $0,2 \mathrm{~m}$. Le comblement pour sa part est toujours constitué de limons très argileux brun-gris, graveleux, et très compacts.

Ces deux fossés peuvent être assimilés à des fossés bordiers délimitant un chemin, large de 6 à $8 \mathrm{~m}$ (fig. 12). En témoignent aussi bien l'indigence en mobilier que leur tracé et leur morphologie. L'hypothèse d'un chemin est renforcée par les données du diagnostic. En effet, ces deux fossés parallèles ont pu être suivis sur plusieurs dizaines de mètres, le fossé 538 ayant livré un peu de mobilier laténien (Nauleau, 2009, fig. 9). Le chemin semble d'ailleurs adopter un tracé légèrement curviligne et se diriger vers le haut du plateau.

Le fossé 538 est bordé à l'ouest par un troisième qui lui est parallèle (F 539), avant de le recouper. Bien que légèrement plus large que F 538, F 539 va également en rétrécissant vers le nord, et n'a pas non plus été retrouvé au nord du fossé moderne. Il présente un profil en cuvette qui atteint au maximum $0,7 \mathrm{~m}$ de largeur pour $0,3 \mathrm{~m}$ de profondeur.
Le comblement de limons argileux est très semblable à celui de F 538, ce fossé n'ayant livré aucun mobilier dans aucun des six sondages qui ont permis son étude. Ainsi, bien qu'il ne puisse être daté, F 539 semble fonctionner avec le chemin gaulois. Il peut être interprété comme un second état du fossé bordier.

Ces fossés n'ont livré que de rares tessons de facture protohistorique. Leur appartenance à l'occupation gauloise (au moins dans sa phase finale) est toutefois suggérée par l'installation d'une urne cinéraire antique dans le comblement de F 535. Au total, ce sont trois incinérations antiques (deux en urnes et une probablement en pleine terre) qui ont été mises au jour au centre et sur le bord occidental du chemin gaulois. La localisation de ces sépultures est relativement classique pour la période antique. Ce petit groupe sépulcral s'inscrit dans un contexte local du Haut Empire documenté par des installations domestiques accompagnées d'autres sépultures (Devals, 2010) et par des fours artisanaux fouillés à quelques dizaines de mètres du site gaulois par $\mathrm{F}$. Mercier (DParch, Nantes Métropole).

Ainsi, les crémations du Bois Hue participent d'ensembles funéraires ruraux du Haut-Empire. Souvent constitués de petits groupes qui vont de deux à un peu plus d'une dizaine de structures, voire parfois de structures isolées, ils sont localisés à proximité de voies, de chemins ou de limites parcellaires (Blaizot, 2009). Ils permettent en tout cas de supposer qu'au moment de leur enfouissement (daté du Haut Empire sans plus de précision), le chemin gaulois était encore visible, voir encore usité. Une datation ${ }^{14} \mathrm{C}$ réalisée sur des charbons provenant du fossé 535 fournit une datation entre 350-300 av. n. è. et $210-60$ av. n. è. (Beta-318933: $2130 \pm 30$ BP).

Un fossé de dimensions modestes est apparu qui suit presque en totalité le tracé du fossé d'enclos (fig. 3). Il lui est parallèle et dégage un espace vide de toute structure large de 2,5 à $4 \mathrm{~m}$. À l'endroit où le fossé d'enclos oblique vers le nord, le fossé 530 poursuit son tracé rectiligne, déviant même légèrement vers le nord-est.

Bien que leur relation ait été détruite par un fossé moderne, le fossé 530 se dirige vers le chemin gaulois. Si l'on considère qu'on ne retrouve aucune trace du fossé 530 à l'est des fossés bordiers, il est alors fort probable qu'ils soient liés, d'autant plus que les caractéristiques du fossé 530 sont très proches de celles des fossés de bord de chemin. Ce fossé mesure environ $0,5 \mathrm{~m}$ de largeur et adopte un profil évasé d'une profondeur moyenne de 0,16 à $0,2 \mathrm{~m}$, conservé au maximum sur $0,3 \mathrm{~m}$. Son comblement est souvent unique, pour autant qu'on puisse le déterminer, composé d'un sédiment argileux très faiblement limoneux, proche du substrat.

Ce type de fossé périphérique qui entoure et double le fossé principal est un aménagement rencontré couramment sur les sites du Second âge du Fer. Pour ne citer que quelques 

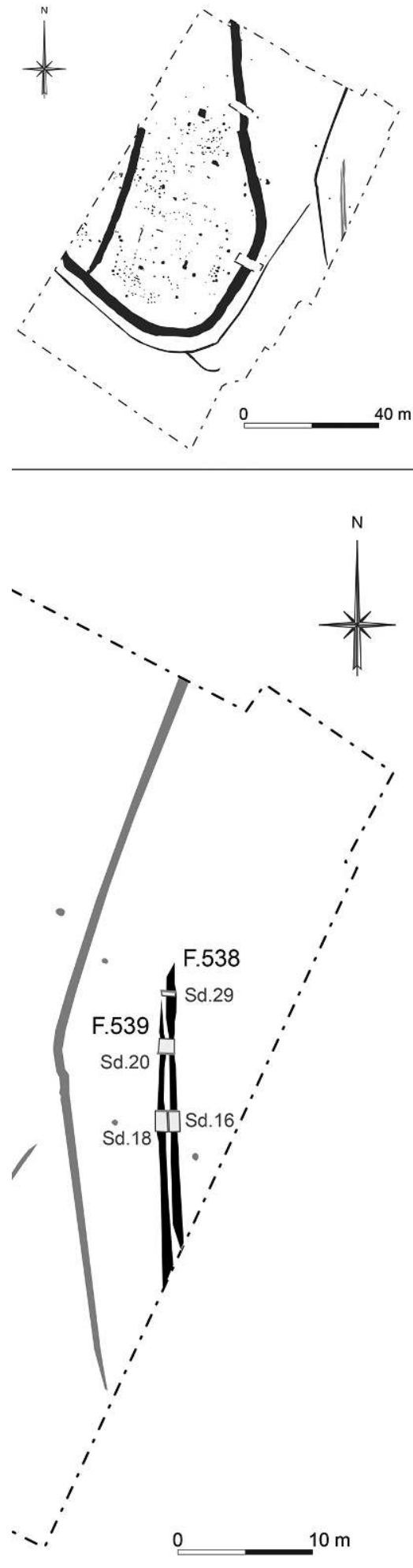
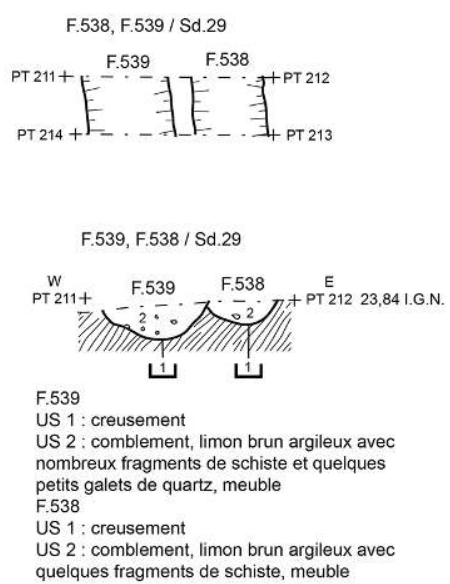

F.538, F.539/Sd. 20
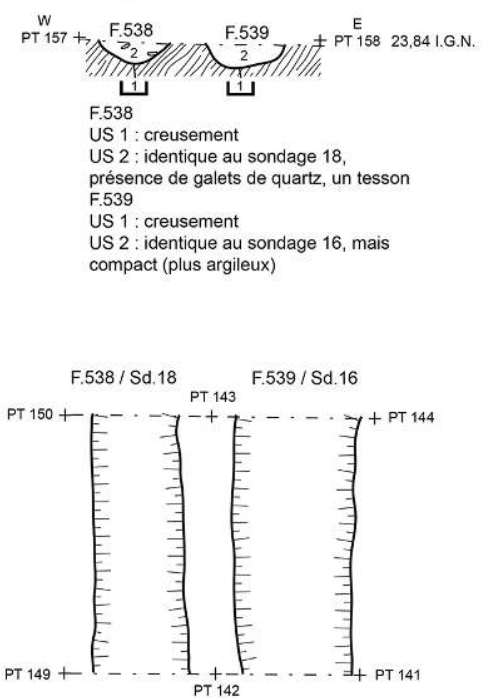
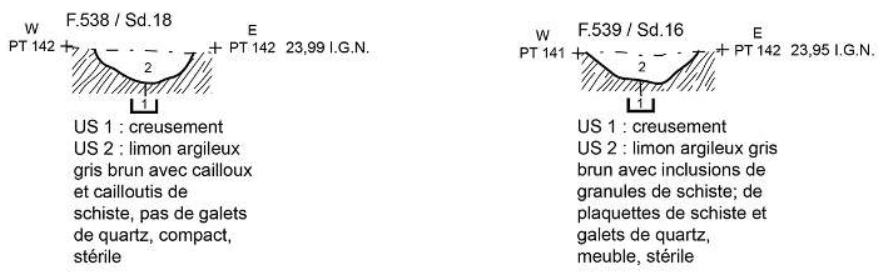

Substrat (schiste)

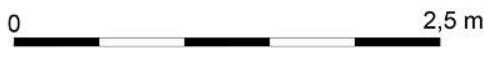

Figure 11 : Plans et coupes des fossés bordiers (E. Boutonnet).

Figure 11: Plans and sections of the borders ditches. 


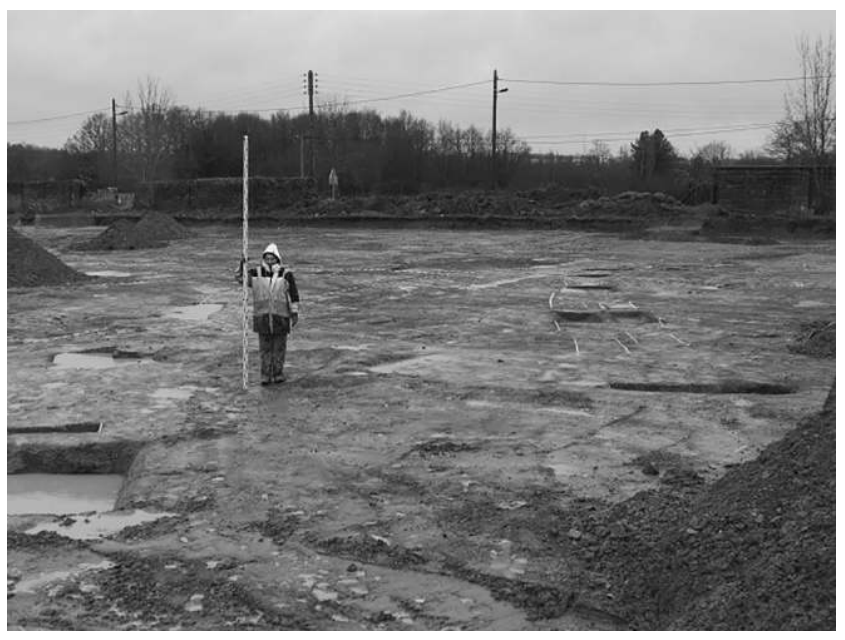

Figure 12 : Vue du chemin vers le nord-ouest (les tas de terre à l'arrière marquent le fossé d'enclos) (A. Levillayer).

Figure 12: View of the path taken looking to the north-west (in the background, heaps of soil indicate the enclosure ditch).

exemples régionaux, on peut mentionner le site voisin de La Bréchetière à Carquefou où le fossé principal est doublé d'un plus petit, libérant un espace vierge de 2 à $4 \mathrm{~m}$ de largeur (Vacher, 1992), celui des Ténauderies à Aigrefeuillesur-Maine (Toron, 2016), et le site de Beauséjour à Angers où l'enclos quadrangulaire est doublé sur toute sa périphérie (Pétorin, 2010), le précédent ne l'étant que partiellement. Ces fossés, qu'on rencontre aussi parfois à l'intérieur de l'enclos (Guérin, 2003), peuvent être interprétés comme des espaces de circulation ou la délimitation d'un talus. Dans le cas du Bois Hue, nous privilégions la première interprétation, eu égard à la physionomie du fossé très proche des fossés bordiers du chemin gaulois, à son association avec eux et à son tracé qui le connecte avec d'autres petits fossés qui n'ont été appréhendés que partiellement (F 535 et F 543), mais qui semblent dessiner des espaces périphériques liés à l'enclos principal.

\section{LE MObILIER du SITE DU BoIS Hue}

\section{La céramique}

\section{La céramique indigène}

Avec 2912 tessons de céramique, dont 2547 tessons de céramique indigène, l'ensemble du Bois Hue fournit un lot conséquent dont l'étude, mise en perspective avec les sites voisins, et en particulier celui du Clouët (Le Goff, 2003), permet de pousser plus avant les réflexions sur le corpus céramique gaulois nantais. À eux deux, les fossés F 545/546 et $\mathrm{F} 547$ concentrent 92,62\% du mobilier céramique, le fossé d'enclos ayant livré à lui seul 1880 tessons $(74,5 \%$ du NR). Au total, on recense 211 individus.

Les pâtes des céramiques découvertes au Bois Hue sont très homogènes. Pour autant que l'examen macroscopique puisse le déterminer, la quasi-totalité d'entre elles sont à base d'argiles détritiques locales (entendues au sens large) qui se caractérisent par des inclusions de quartz (parfois très grossières) et de mica. Certains individus présentent des concentrations de mica très importantes. Cette production représente près de $75 \%$ du lot étudié. L'étude a permis de définir vingt-deux types, dont certains présentent des variantes répétitives et suffisamment caractéristiques pour donner naissance à des sous-types.

La typologie céramique corrélée à la stratigraphie qui avait schématiquement distingué trois grandes étapes de comblement du fossé d'enclos, permet de proposer une évolution phasée du fonctionnement du site, et par là même une chrono-typologie entre La Tène B2 et La Tène D1.

\section{- L'horizon 1 (La Tène B2)}

Les types céramiques les plus anciens découverts au Bois Hue inscrivent la fondation du site dans le courant de La Tène ancienne (fig. 13). À l'exception de quelques vases, la presque totalité du matériel provient des premiers niveaux de comblement, aussi bien du fossé d'enclos, que du fossé de partition, ce qui permet d'affirmer leur contemporanéité.

On rencontre parmi les formes fréquentes de cet horizon, des vases tronconiques à parois rectilignes caractérisés par des lèvres infléchies (fig. $13, \mathrm{n}^{\circ} 1$ et 2 ). Ils sont fréquents dans la région et on les rencontre par exemple en Loire-Atlantique à La Tène ancienne à Ancenis (Viau, 2010, fig. 130) et à La Galonnière à Saint-Philbert-de-Grandlieu ${ }^{1}$ où ils coexistent avec un vase à parois concaves très proche de celui du Bois Hue (fig. 13, no 3 ). Cette forme, ornée très fréquemment de digitations, n'est pas sans rappeler les corpus « jogassiens » de l'Est de la France (Demoule et al., 2009, fig. 10, n 23). Les jattes à profil en $S$, relativement « archaïques » du fait d'une liaison $\mathrm{col} /$ panse bien marquée (fig. 13, $\mathrm{n}^{\circ} 7$ ), sont bien représentées dans cet assemblage, ce qui indique un ancrage dans une Tène déjà bien avancée. L'unique vase tourné de cet ensemble (fig. 13, $\mathrm{n}^{\circ} 6$ ) évoque les formes largement documentées en Bretagne (Menez, 1996) qui peuvent être attribuées à la fin du IV et au III ${ }^{e}$ siècle. En Loire-Atlantique, on les rencontre en particulier dans le Pays de Retz à la même période (Levillayer, 2007; Vacher, 2000). Les vases à haut col sont parmi les types les plus caractéristiques (fig. 13, $\mathrm{n}^{\circ} 8$ à 10). Le vase $\mathrm{n}^{\circ} 8$ se rencontre dans le corpus déjà cité

1. Ce site fouillé par P. Bellanger (2000) semble relever principalement $\mathrm{du} \mathrm{IV}^{\mathrm{e}}$ et du début du $\mathrm{III}^{\mathrm{e}}$ s. av. n. è. Deux datations 14C appuient cette datation; nous les rappelons ici à titre indicatif; Lyon-3535: $2230+-30$, soit 387-204 av. n. è. et Ly-19703 : 2200+-35, soit 377-182 av. n. è. 

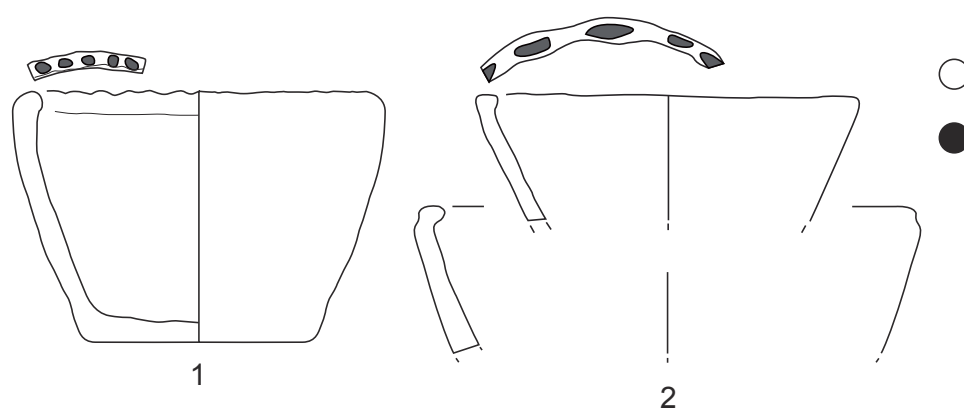

céramique non tournée

céramique tournée
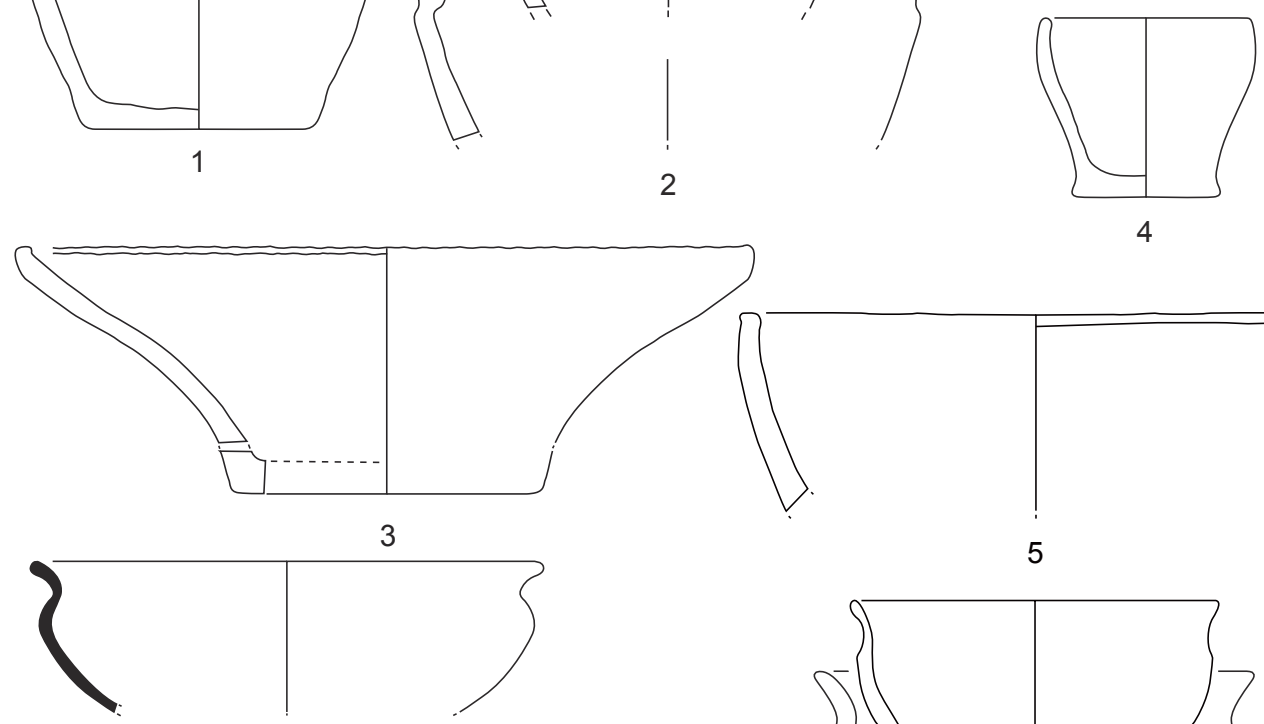

6
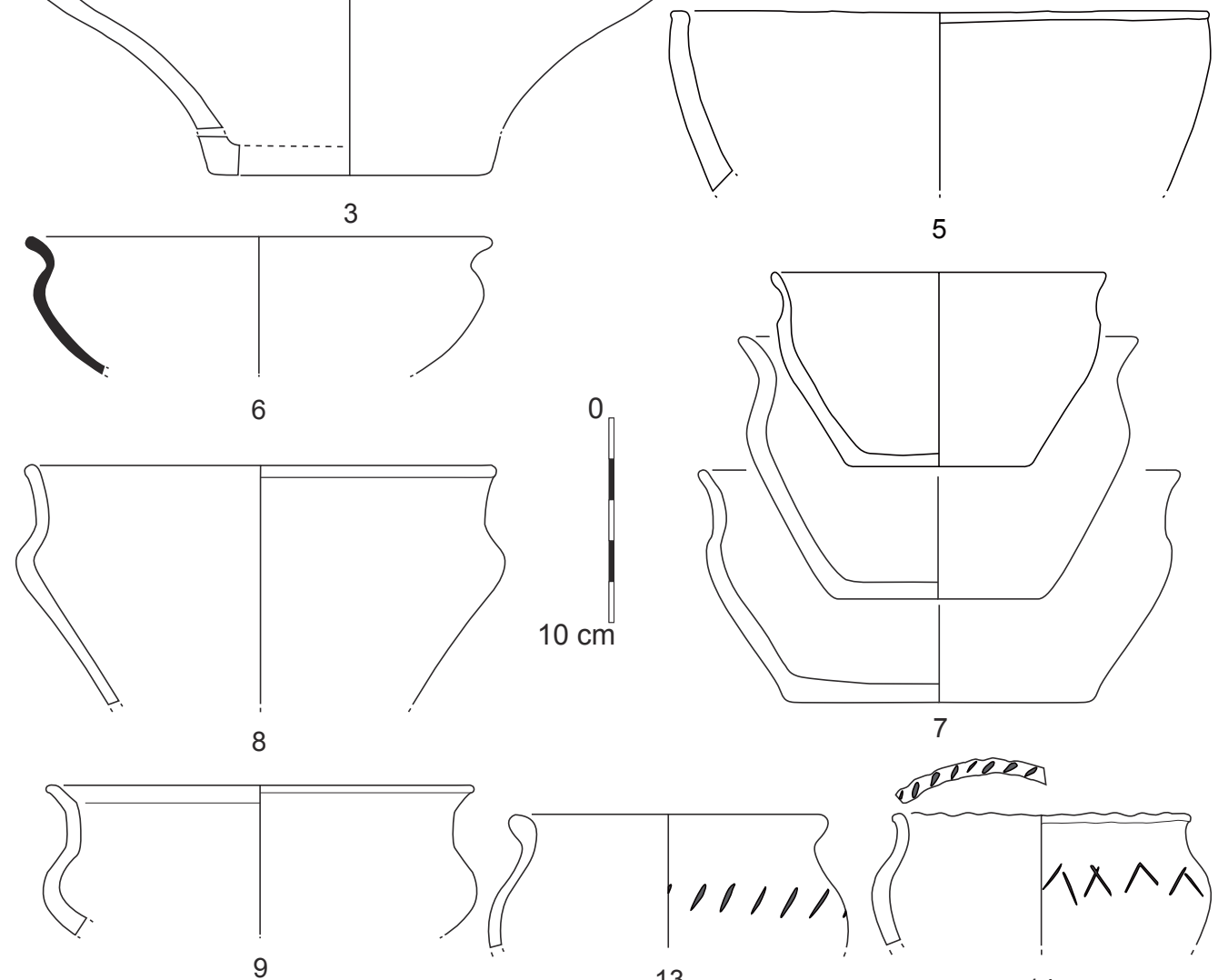

ateed

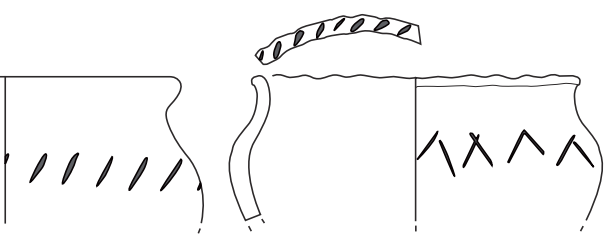

13

14

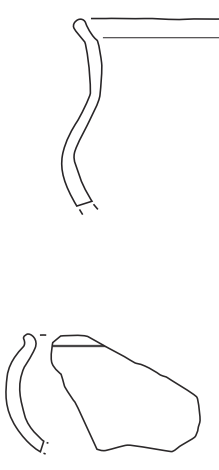

11

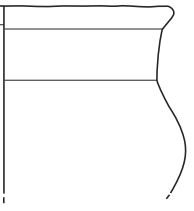

10

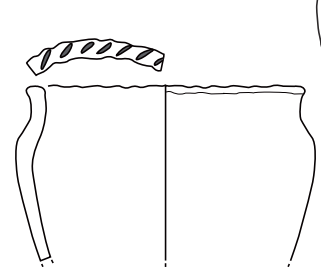

12

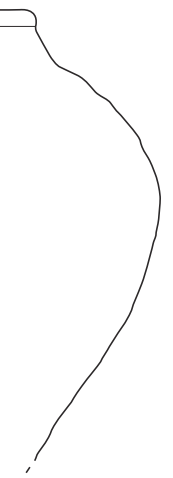

15

Figure 13 : Mobilier céramique de La Tène B (2 ?) (A. Levillayer).

Figure 13: Pottery of La Tène B. 
de La Galonnière, mais également dans le Maine-et-Loire sur les sites de La Tène A de La Morinière à Chanzeaux (Le Goff, 1999, pl. 6) ou de Richebourg à Trémentines (Pithon, 1999, fig. 46). Sur ce dernier site, l'auteur rapproche ces vases, à juste titre, de formes documentées en Gaule de l'Est à La Tène ancienne (Hatt et Roualet, 1981) et qui se diffusent largement, ainsi que l'attestent les vases du Iv ${ }^{e}$ siècle de l'enclos IV-V de Coulon (Deux-Sèvres) où un exemplaire proche de celui de Nantes, quoiqu'à carène légèrement plus basse, a été découvert (Pautreau, 2007, fig. 4). Les exemplaires à haut col cylindrique et lèvre à méplat (fig. 13, nº 9 et 10) sont pour ainsi dire canoniques de La Tène ancienne, et caractérisent les ensembles régionaux de La Tène A et $\mathrm{B}$. Documentées du Centre-Ouest (Gomez de Soto et al., 2007, p. 75) à la Bretagne, par exemple dans la phase II ancienne du site du Boisanne à Plouër-sur-Rance, datée du Iv ${ }^{e} s$. av. n. è. (Menez, 1996, p. 107-108), on les retrouve largement dans la basse vallée de la Loire (Levillayer et al., 2013). Dans le Centre-Ouest, ces vases semblent plutôt marquer les phases tardives de La Tène ancienne, soit La Tène B1/B2 (Gomez de Soto et al. 2007, fig. 8 et 9). Parmi les formes hautes, qui portent pour une majorité des décors digités et/ ou incisés, on note des vases aux panses très galbées (fig. 13, $\mathrm{n}^{\circ} 13$ et 14), dont un exemplaire n'est pas sans rappeler, du fait de sa lèvre épaissie, des vases de La Tène B connus en Centre-Ouest (Gomez de Soto et al., 2007, fig. 10). Deux vases à panse globulaire et col court resserré (fig. 13, n ${ }^{\circ} 15$ ) renvoient aux mêmes contextes, puisqu'ils trouvent des affinités avec des formes provenant de Mazerolles (Vienne) qui entrent dans la définition d'un horizon La Tène B2/C1 (Gomez de Soto et al., 2007, fig. 9).

L'ensemble des éléments présentés inscrit donc clairement ce premier horizon dans La Tène ancienne. On a noté les nombreuses analogies avec les ensembles locaux et avec ceux du Centre-Ouest, dont la sériation isole des éléments caractéristiques d'une phase plutôt tardive de La Tène ancienne. Il semble donc qu'il faille envisager une fondation de l'établissement dans le courant du IV ${ }^{e}$ s. av. n. è., et probablement plutôt à la fin de celui-ci.

\section{- L'horizon 2 (La Tène C1)}

Ce second horizon est plus difficile à cerner, en raison d'une part de la moindre quantité de mobilier recueillie dans les niveaux intermédiaires du comblement des fossés, et d'autre part de l'absence de type réellement discriminant. Son attribution chronologique est basée en grande partie sur son rapport aux ensembles antérieur et postérieur, sa constitution étant pour sa part fondée exclusivement sur la position des vases dans la stratigraphie ${ }^{2}$. Une datation réali-

2. Ceci implique que des vases plus anciens aient été insérés dans cet horizon (en cas de résidualité), ou qu'au contraire, d'autres qui aient par- sée à partir d'un charbon provenant du niveau intermédiaire du remplissage du fossé d'enclos, entre la couche argileuse la plus ancienne et le comblement supérieur riche en mobilier, fournit un intervalle de probabilité compris entre 390 et $210 \mathrm{av}$. n. è. (Beta-318935: $2280 \pm 30 \mathrm{BP}$ ) qui corrèle l'attribution chronologique établie.

Une des caractéristiques marquantes de cet horizon est qu'il rompt avec les formes précédemment rencontrées, alors qu'il porte en germe celles qui vont perdurer ou évoluer jusqu'à l'abandon du site (fig. 14). En effet, si les formes tronconiques sont surreprésentées, à l'image d'un constat désormais établi pour toute la basse vallée de la Loire (Cornec et al., à paraître) et dans l'est de la Bretagne (Le Goff, 2003), les écuelles à profil en $S$ (fig. 14, $\mathrm{n}^{\circ} 3$ à 8 ) deviennent majoritaires. Certaines, tournées (fig. 14, $n^{\circ} 3$ ), présentent une lèvre épaisse déjetée et une panse rebondie qu'on trouve dans la région dès le début $\mathrm{du} \mathrm{III}^{\mathrm{e}}$ siècle, notamment dans le Maine-et-Loire, à Beaupréau (Levillayer et Prigent, 2010, fig. 6, no 4a) ou Écouflant (Nillesse, 2004). Elle connaît une forte diffusion au cours des $\mathrm{III}^{\mathrm{e}}$ et $\mathrm{II}^{\mathrm{e}}$ siècles av. n. è., dans la phase II récente des Natteries à Cholet par exemple (Maguer, 2000, fig. 99, $\mathrm{n}^{\circ}$ 104) ou dans le Pays de Retz (Levillayer, en préparation). La même évolution est constatée en Bretagne, par exemple au Boisanne à Plouërsur-Rance (Côtes-d'Armor) où cette forme est documentée à la phase III ancienne (soit entre 250 et 150 av. n. è.) pour être remplacée par d'autres jattes à profil en $S$ par la suite (Menez, 1996, fig. 99, n² 24). Le vase à carène marquée et col droit (fig. 14, $\mathrm{n}^{\circ}$ 5) est connu localement, au Clouët à Carquefou, dans un ensemble de la phase 1 (F 30) datée du III ${ }^{\mathrm{e}}$ siècle (Le Goff, 1998, pl. 1). Dans sa périodisation pour le Bassin parisien, S. Marion place cette forme aux étapes 7 et 8 , soit entre la fin de La Tène $\mathrm{C} 1$ et la fin de La Tène C2 (Marion, 2004, fig. 207 et 208). Une importante série de vases à profil en $S$ à épaulement haut et lèvre " en gouttière " (fig. 14, $n^{\circ}$ 6) marque cet ensemble. En Loire-Atlantique, ce type est caractéristique du Pays de Retz où, par analogie notamment avec les découvertes faites en Bretagne, il est attribué aux contextes de La Tène moyenne, ainsi qu'en attestent les découvertes des Moutiers-en-Retz (Levillayer, 2007) ou de Saint-Philbert-de-Grandlieu (Vacher, 2000). Parmi les formes hautes, qui sont les seules à présenter encore quelques rares décors digités ou incisés, le vase $\mathrm{n}^{\circ} 9$ se réfere à nouveau à une forme du Clouët datée du III $^{\mathrm{e}}$ siècle (Le Goff, 1998, pl. 1) et connue également sur l'habitat aristocratique des Natteries entre l'extrême fin du III $^{e}$ et le premier tiers du II ${ }^{\mathrm{e}}$ s. av. n. è. (Maguer, 2007, p. 76-77).

ticipé de cet horizon n’y figurent pas, parce que retrouvés dans les niveaux supérieurs. Ces phénomènes restent cependant marginaux. 

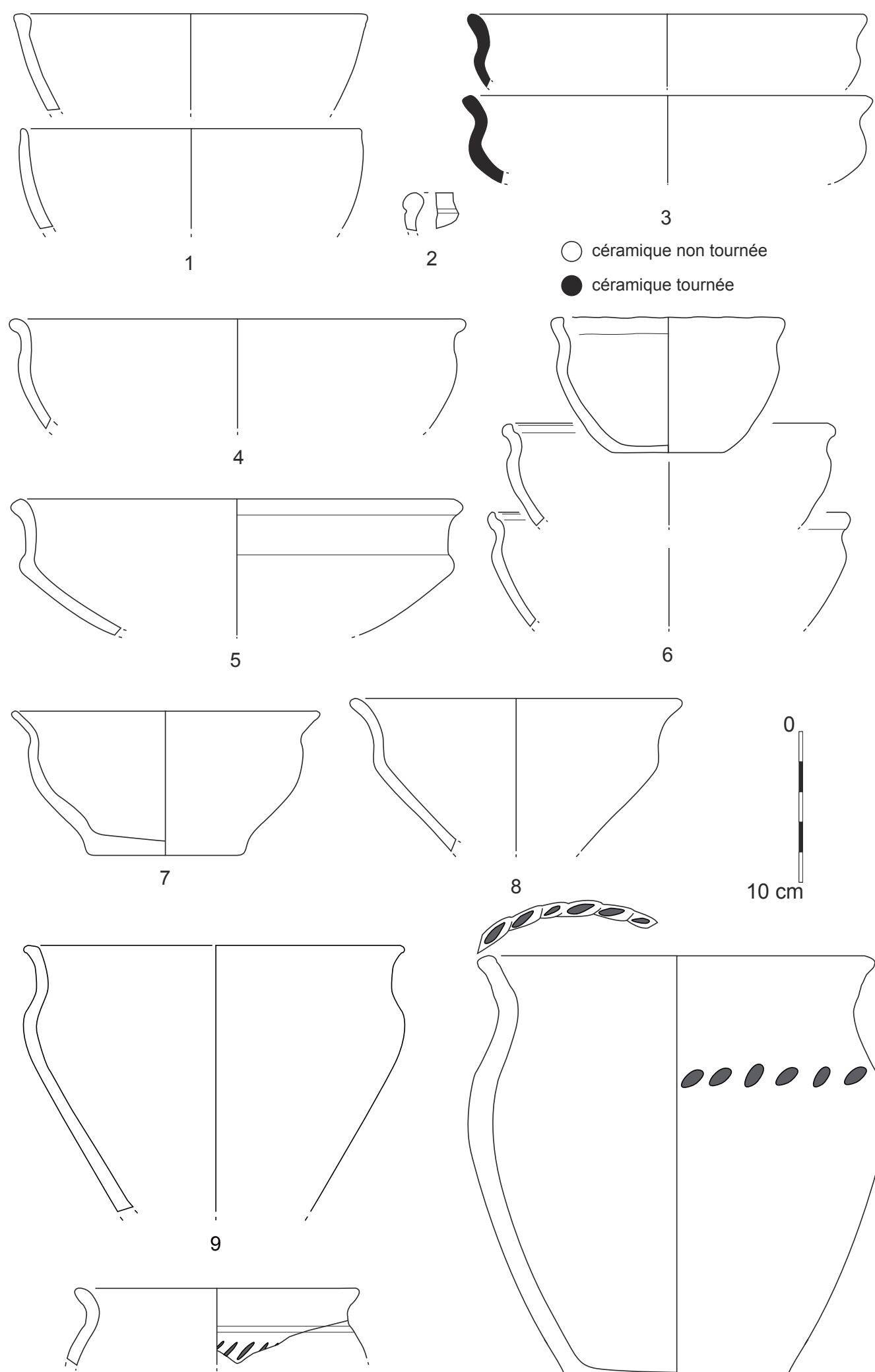

11

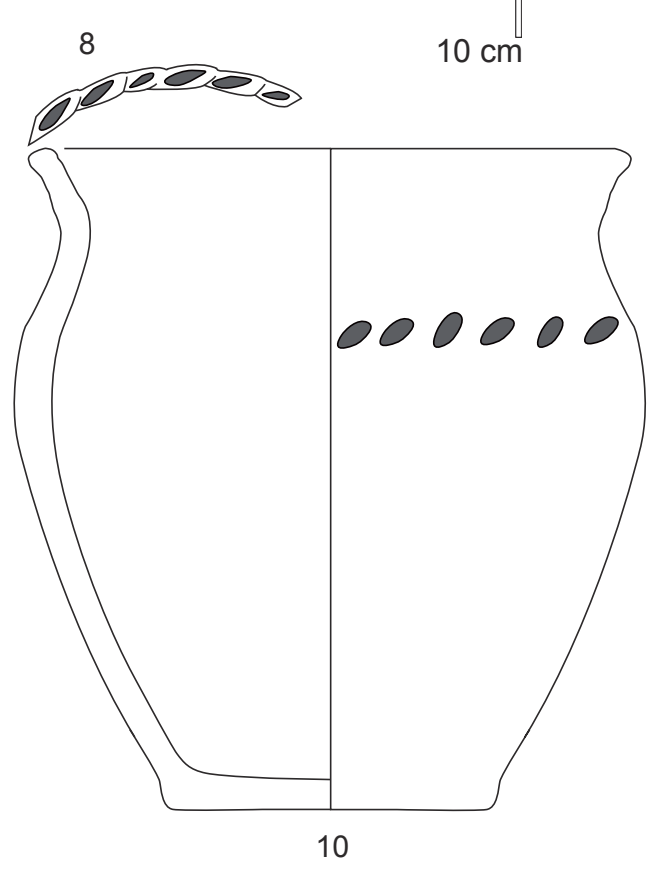

Figure 14 : Mobilier céramique de La Tène C1 (A. Levillayer).

Figure 14: Pottery of La Tène C1. 
Centré sur La Tène C1, cet ensemble apparaît contemporain de la première phase d'occupation du site du Clouët à Carquefou (Le Goff, 2003), ainsi que le confirment l'examen conjoint des lots.

\section{- L'horizon 3 (La Tène C2/D1)}

Le dernier niveau de comblement est le plus riche en mobilier. Le faciès céramique (fig. 15) est largement dominé par les formes tronconiques qui présentent une grande diversité morphologique des lèvres (fig. $15, \mathrm{n}^{0} 1$ à 3 ). Les écuelles à profil en $S$ sont globulaires et les cannelures labiales disparaissent (fig. $15, \mathrm{n}^{\circ} 4$ et 5). Des formes plus originales à l'échelle du site font leur apparition. On signalera ainsi un vase à profil en $S$ exagérément évasé (fig. 15, nº 6). Au Clouët, ces vases sont attribués à la phase 1 datée de la première moitié du III ${ }^{\mathrm{e}}$ siècle av. n. è.; ils sont ornés de digitations sur la lèvre (Le Goff 1998 : pl. 5). Régionalement, ce type apparait ponctuellement dans des contextes dont la datation est centrée sur la fin du III et le début du II ${ }^{\mathrm{e}}$ siècle av. n. è. (La Tène C1/C2) : aux Natteries à Cholet durant la phase II récente (Maguer, 2000, fig. 99, $\mathrm{n}^{\circ}$ 101.7), ou encore au début du $\mathrm{II}^{\mathrm{e}}$ siècle aux Chaloignes à Mozé-sur-Louet (Levillayer, 2006, fig. 6). Un gobelet tronconique à cordons se distingue (fig. 15, no 7). Cette forme qui est bien documentée dans le Maine-et-Loire, l'est beaucoup moins en Loire-Atlantique avec seulement deux sites (le Bois Hue et la Savinière 1 à Ancenis). L'analyse chronologique du corpus a montré que la datation de cette forme était centrée sur La Tène C2 (Cornec et al., à paraître, type 49b). Un vase unique découvert au sommet du fossé de partition se caractérise par une panse cannelée surmontée d'une lèvre en bourrelet triangulaire (fig. $15, \mathrm{n}^{\circ} 8$ ). Son décor de cordons rappelle une écuelle à carène surbaissée découverte au Clouët à Carquefou, attribuée à la phase 3 datée du début de La Tène D1 (Le Goff, 1998) mais, à notre connaissance, elle ne trouve pas - sa lèvre en particulier - d'équivalent exact. Une parenté peut toutefois être suggérée avec des vases baquets tels qu'on en rencontre par exemple aux Pichelots aux Alleuds (Maine-et-Loire), et sur des sites attribués à La Tène D2, à Vil-Mortagne en Charente-Maritime par exemple (Landreau, 2009, fig. 28, n 3), ou encore avec les gobelets à lèvre en bourrelet des ensembles bretons de La Tène finale, à Saint-Glen, Locquirec ou encore aux Ebihens (Daire, 1992, pl. XVIII, $\mathrm{n}^{\circ} 4$; pl. XIX, no 2 et 6 ). Les formes fermées hautes sont bien représentées dans cet horizon. Les pots à parois verticales de petit module (fig. 15, $\mathrm{n}^{\circ} 9$ et 10) sont largement documentés dans la région pour les deux derniers siècles avant notre ère (Cornec et al., à paraitre, types 56). Une série de pots à cordons présentant pour beaucoup des décors incisés ou à la pointe mousse et pour quelques-uns des cannelures labiales, s'inscrivent dans les contextes laténiens récents (Daire, 1992). La même association entre cannelures labiales, cordons sur le col et décors incisés a été constatée au Clouët, dans les phases attribuées au début de La Tène finale (Le Goff, 1998). Les pots de stockage (fig. $15, \mathrm{n}^{\circ} 14$ ) sont spécifiques à cet horizon et semblent, régionalement, marquer La Tène D1. Les vases de type "Besançon " (au moins cinq exemplaires) sont eux aussi exclusifs du faciès le plus récent. On trouve des lèvres arrondies éversées et des lèvres triangulaires. Si l'on suit la chrono-typologie établie pour l'Allier, le vase $\mathrm{n}^{\circ} 16$ se place entre la fin de La Tène C2 et La Tène D1 (Lallemand et Tuffreau-Libre, 2005, fig. 26), alors que le $\mathrm{n}^{\circ} 15$ se placerait à La Tène D1 (Lallemand et Tuffreau-Libre, 2005, fig. 25).

L'étude montre que si certaines formes indiquent La Tène D1, une majorité semble trouver des équivalences dans les contextes de la fin de La Tène moyenne. Malheureusement, il n'est pas possible de distinguer plus finement La Tène C2 de La Tène D1. D'un point de vue de la seule céramique indigène, il est difficile de poser des bornes chronologiques précises, mais, à l'exception peut-être du vase $\mathrm{n}^{\circ} 8$, aucun marqueur d'un $\mathrm{I}^{\mathrm{er}}$ siècle avancé n'a été découvert, laissant envisager une date d'abandon plutôt haute dans ce siècle, voire à la fin du $\mathrm{II}^{\mathrm{e}}$ siècle, ce que semblent confirmer le mobilier amphorique.

\section{Les amphores (V. Audé)}

Le site du Bois Hue a livré un lot intéressant de fragments d'amphores à l'échelle régionale, avec un total de 365 tessons, dont 18 fragments de bords, 19 fragments d'anses (attaches supérieures, sections, attaches inférieures), 54 fragments de cols, 7 fragments d'épaules, 232 fragments de panses, 19 fragments de fonds et 6 pieds, pour un poids total de $18,6 \mathrm{~kg}$ et un NMI de 12 (fig. 16). La presque intégralité du corpus provient du niveau supérieur du comblement du fossé d'enclos.

L'étude s'est attachée, pour la définition typologique, à la morphologie de la lèvre, considérée aujourd'hui comme un critère discriminant majeur (Loughton, 2000; Maza, 1998; Poux, 1998). Cinq bords appartiennent à la classe $1 \mathrm{de}$ V. Guichard. La hauteur de la lèvre est inférieure à $35 \mathrm{~mm}$ et l'inclinaison est comprise entre 45 et $70^{\circ}$. La production de ce type d'amphore italique républicaine est attribuée à La Tène C2.

Cinq lèvres se rapportent aux classes 1 ou 2 de V. Guichard, la hauteur de la lèvre étant comprise entre 30 et $35 \mathrm{~mm}$ et l'inclinaison de celle-ci variant entre $50^{\circ}$ et $70^{\circ}$. Ce type d'amphore italique républicaine est produite à $\mathrm{La}$ Tène C2-D1.

Deux bords sont de la classe 2 de V. Guichard. Ils sont caractérisés par une hauteur comprise entre 30 et $60 \mathrm{~mm}$ et une inclinaison de 50 et $70^{\circ}$. La production de ce type de récipient est attribuée à La Tène D1a. 

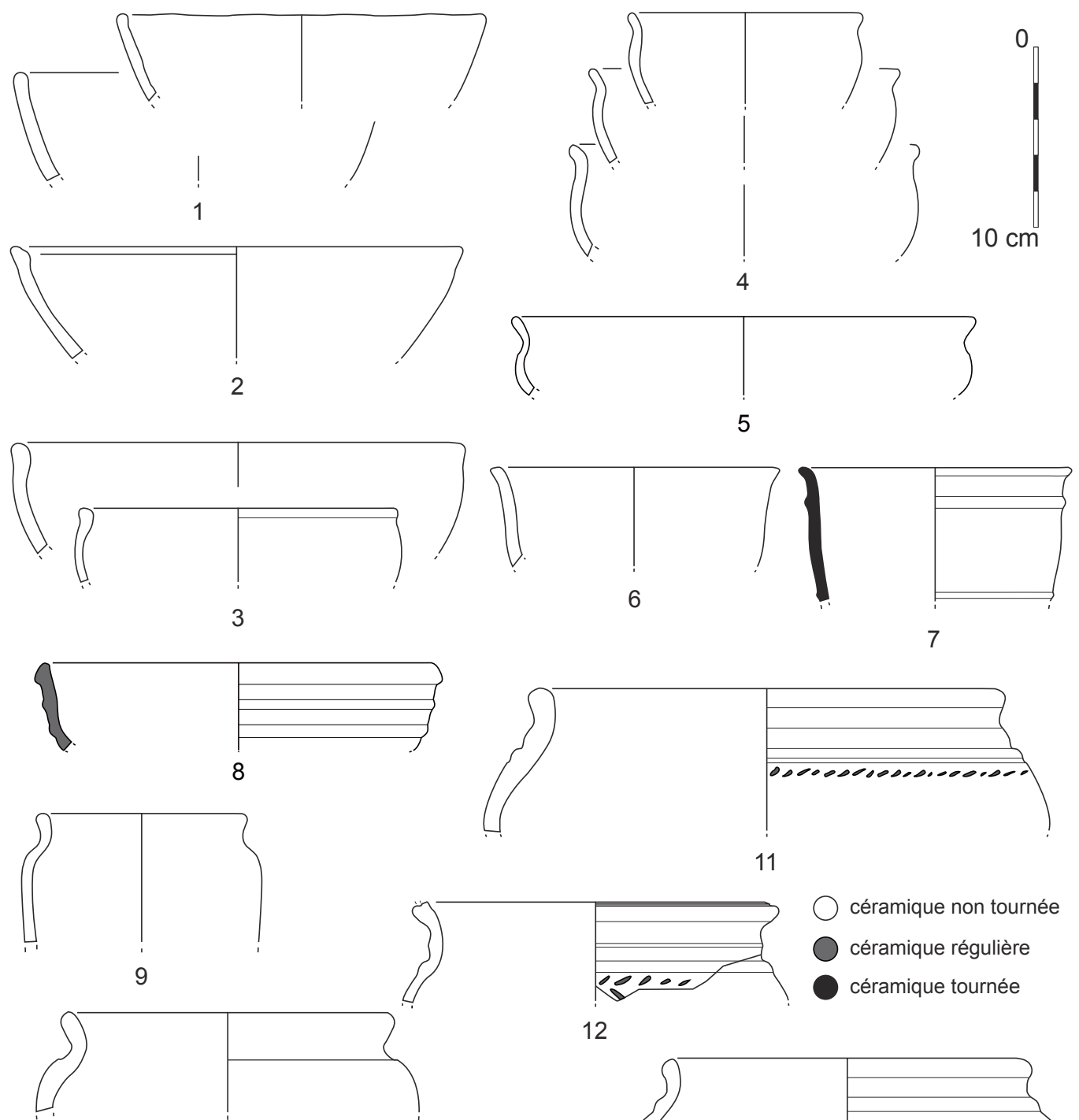

5

10
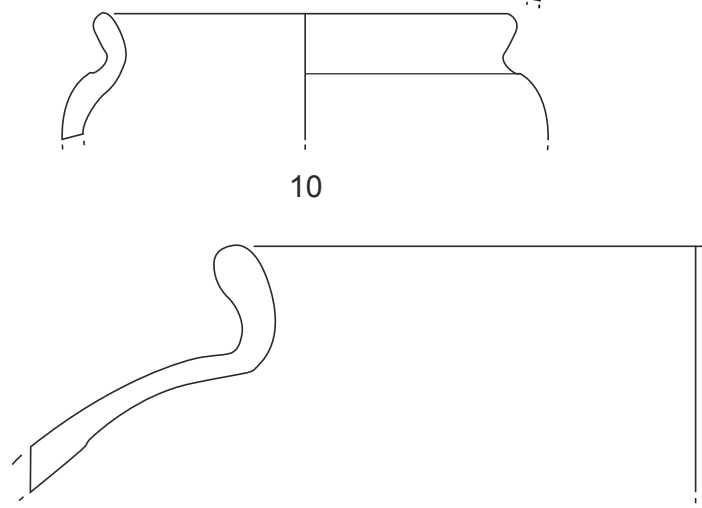

14

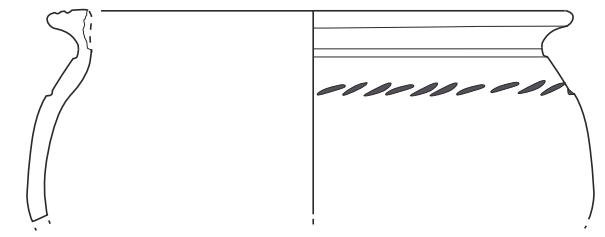

15

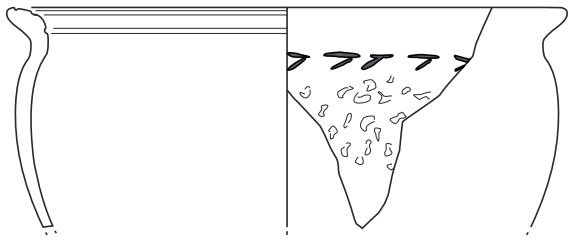

16

Figure 15 : Mobilier céramique de La Tène C2/D1 (A. Levillayer).

Figure 15: Pottery of La Tène C2/D1. 

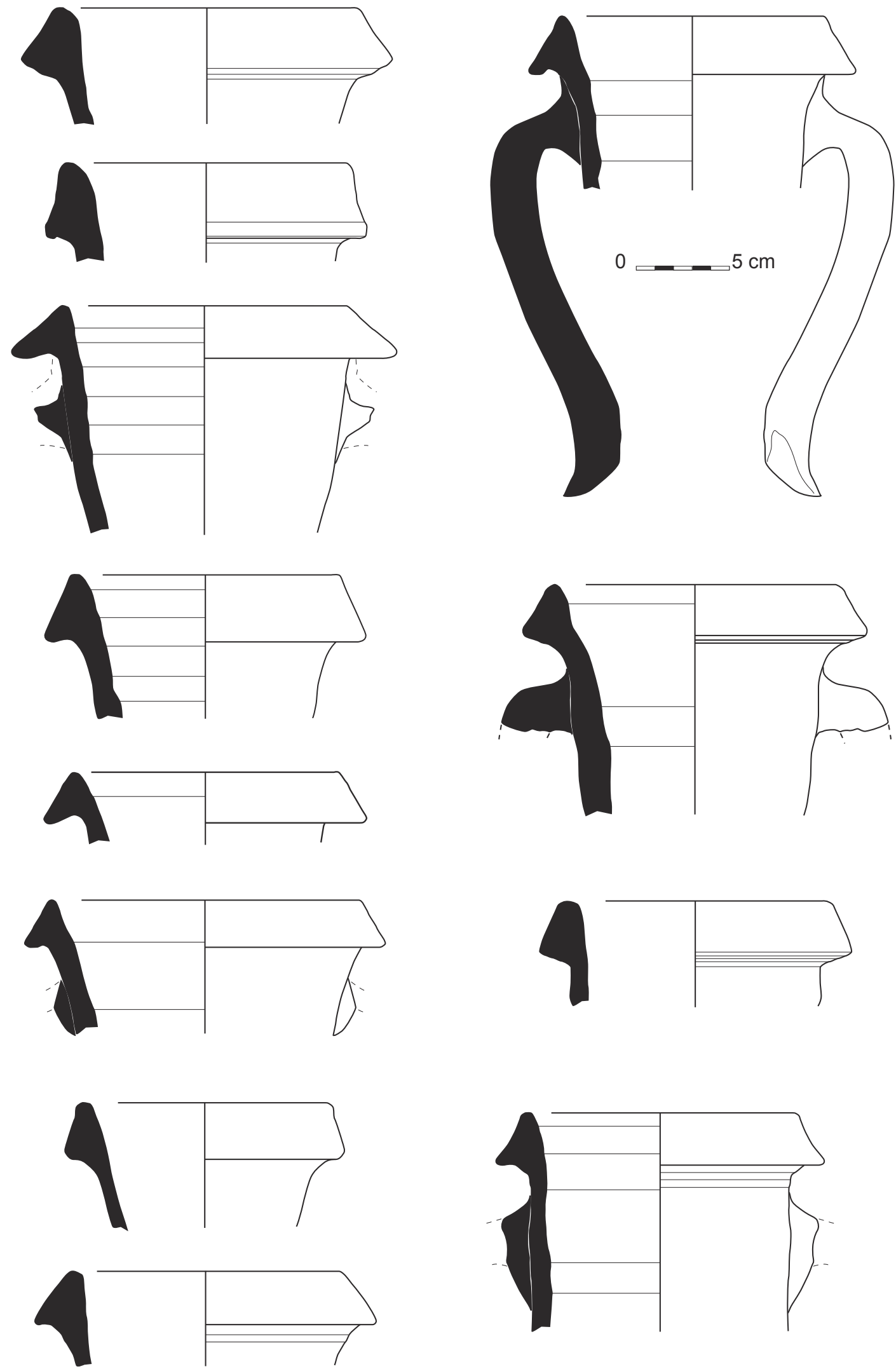

Figure 16 : Amphores italiques découvertes dans le fossé d'enclos (V. Audé).

Figure 16: Italic amphorae discovered in the enclosure ditch. 
Parmi les douze individus déterminés, on compte donc cinq amphores de type Gréco-italique, cinq de type Grécoitalique de transition Dressel 1A et deux de type Dressel 1A. On observe un apport légèrement plus important d'amphores gréco-italique de transition Dressel 1A. L'ensemble de ce mobilier paraît homogène et évoque des assemblages caractérisant La Tène C2-D1a.

L'inventaire et l'étude macroscopique (observation à l'œil nu ou à la loupe binoculaire) du mobilier amphorique ont permis de faire apparaître la diversité des approvisionnements en vin. Les trois régions italiques de production (Étrurie, Latium et Campanie) sont présentes en plus ou moins grande quantité. L'Étrurie est représentée par 85 tessons dont quatre individus différents pour un poids total de 3,3 kg. Le Latium et la Campanie sont présents dans les mêmes proportions du point de vue quantitatif, soit un peu plus de $7 \mathrm{~kg}$. Au moins trois amphores différentes sont dénombrées parmi les 198 fragments provenant du Latium, et quatre parmi les 59 tessons provenant de Campanie.

Caractérisé par un imposant fossé, cet établissement rural livre un mobilier amphorique qui trahit un statut particulier. Sans qu'on puisse évidemment évoquer un site aristocratique, il semble se rattacher à une série d'établissements bien dotés en amphores avec un NMI supérieur à 10, notamment celui voisin du Clouët à Carquefou (Le Goff, 2003), et dans une moindre mesure celui de la Bréchetière sur la même commune (Vacher, 1992). Ces données concourent-elles à caractériser un espace favorisé? En amont de la Loire, dans le département du Maine-et-Loire, quelques sites livrent des ensembles similaires (Cornec et al., à paraître) qui pourraient surtout mettre en lumière le rôle majeur de l'axe ligérien, et ce faisant celui des établissements qui le bordent.

\section{Les autres mobiliers}

\section{Les terres cuites: pesons, plaques foyères et augets à sel}

Les terres cuites sont représentées par 2980 restes, pour un poids total de $131 \mathrm{~kg}$. Il s'agit le plus fréquemment de fragments informes d'argile cuite. Plusieurs types de restes ont pu être identifiés : 33 fragments de pesons tronc-pyramidaux, des fragments de torchis clayonné provenant entre autres des structures internes à l'enclos, et une trentaine de fragments de plaques foyères. Il s'agit de "plaques rectangulaires aux angles parfois arrondis [...] qui présentent parfois un petit bourrelet qui peut marquer le rebord de la plaque » (Le Goff, 2003, p. 111-112). Présentant parfois des traces de passage au feu, il s'agit probablement de soles mobiles qui pouvaient être disposées sur les braises et assuraient une cuisson indirecte des aliments. Deux modules ont pu être distingués qui se fondent sur l'épaisseur des plaques foyères. On trouve en effet d'une part des plaques de 4 à $6 \mathrm{~cm}$ d'épaisseur, et d'autre part des plaques plus fines, dont l'épaisseur est comprise entre 2 et $3 \mathrm{~cm}$. Cette distinction relève peut-être de fonctions différentes. Il est à cet égard intéressant de constater que les plaques épaisses sont majoritairement dépourvues de bourrelet, alors que les plaques plus fines semblent en présenter plus fréquemment, sans qu'il s'agisse d'un caractère systématique. Une plaque se distingue par une forme qui pourrait être très circulaire. Un autre exemplaire a la particularité d'être conservée sur toute sa largeur. Il s'agit d'une plaque épaisse, légèrement bombée, qui montre que ces éléments de cuisson mobiles n'étaient pas forcément très larges. Ici, elle atteint $26 \mathrm{~cm}$, juste avant l'extrémité arrondie.

Signalons qu'aucune distinction chronologique n'a été constatée, les différentes plaques se rencontrant dans les différents niveaux de comblement, quoiqu'elles soient bien moins nombreuses dans les niveaux les plus anciens (cela reflète probablement la modestie des mobiliers anciens en général).

Un possible bourrelet d'auget à sel a été mis au jour dans le fossé d'enclos, qui vient s'ajouter à une lèvre de godet découverte lors du diagnostic (Nauleau, 2009, p. 41) dont la datation, si l'on admet le schéma établi par M. Tessier $(1980$; 2003) et révisé par nous-mêmes (communication orale : atelier « Sel » du PCR Bronze Pays de la Loire, 7 mars 2016, Les Lucs-sur-Boulogne), est plus haute que celle des augets à bourrelet, mais qui pourrait perdurer jusqu'au Iv ${ }^{\mathrm{e}}$ siècle av. n. è.

Deux fonds d'augets à sel ont également été découverts dans les niveaux supérieurs du fossé 545 . Très fragmentés, ils peuvent tout aussi bien relever d'augets à bourrelet que d'augets tronc-prismatiques tels qu'on en emploie sur le littoral guérandais et retzien dans les deux derniers siècles avant notre ère.

Ces quelques éléments montrent donc que tout au long de son histoire, les habitants du Bois Hue ont importé du sel, depuis le littoral de Loire-Atlantique, et plus probablement depuis le Pays de Retz (au moins pour les récipients à bourrelets sommitaux).

\section{Le macro-outillage lithique (E. Mens)}

Le corpus (26 éléments de mouture étudiés) est marqué par la présence d'un fragment de meule rotative (type meta) et de trois meules (ou fragments de meules) dormantes. On compte par ailleurs six éclats de meules dont la typologie reste indéterminée. La fragmentation ne permet pas la restitution fiable du diamètre initial de la meule rotative. Les meules sont en granite ou en gneiss, des roches disponibles sur le sillon de Bretagne tout proche. Les roches d'origine sédimentaires sont très peu fréquentes; on trouve seulement 2 éléments de grès. 
Si meules rotatives et dormantes sont fort différentes d'un point de vue technique, elles sont en revanche constituées du même leucogranite à grain moyen riche en biotite, de sorte que l'on peut proposer une provenance unique dans les deux cas. Le reste des éléments est façonné dans un granite à gros grains, sans pour autant qu'il soit en ce cas possible de déterminer une seule et unique source d'approvisionnement.

Deux éléments retiennent particulièrement l'attention : la fragmentation et la rubéfaction. En effet, aucune meule n'est entière et les plus gros éléments sont ponctués de départs de matière. La rubéfaction concerne 18 pierres sur un total de 26. La rubéfaction totale est la plus fréquente puisqu'elle concerne la moitié des pierres. Vient ensuite la rubéfaction partielle (au moins une face) relevée sur 8 éléments.

Concernant la fonction des meules dormantes, il faut souligner que les surfaces lustrées montrent un usage intensif. Sur la partie active d'une meule dormante découverte dans le fossé d'enclos, la présence de taches rougeâtres nous a conduits à nous interroger sur l'origine et la nature de celles-ci. Il s'agit d'un dépôt très ponctuel de couleur rouge de $4 \times 2 \mathrm{~mm}$ sur la surface active. L'observation à la loupe binoculaire permet d'affirmer qu'il ne s'agit pas d'oxyde de fer naturellement présent dans la pierre, mais bien d'un dépôt, en surface, et conservé dans une petite anfractuosité. L'hypothèse d'ocre ou d'hématite peut être formulée, qui est renforcée par l'aspect fin et pulvérulent du dépôt, mais qui demanderait à être confirmée par une analyse au MEB.

Notons enfin qu'au Bois Hue, comme au Clouët, aucun fragment de meule rotative n'a été découvert dans les niveaux les plus anciens, ce qui corrobore les observations régionales qui attribuent au courant des $\mathrm{III}^{\mathrm{e}}$ et $\mathrm{II}^{\mathrm{e}}$ siècle av. n. è. l'apparition de cette technique (Buchsenschutz et al., 2011).

\section{Un fragment de jais (A. Baron)}

Un fragment de jais brut a été découvert, qui provient des derniers comblements du fossé d'enclos principal, à son intersection avec le fossé de partition. De forme oblongue, il mesure environ $2 \mathrm{~cm}$ de long, pour une épaisseur d'environ $1 \mathrm{~cm}$ (fig. 17). Il est caractérisé par une cassure conchoïdale et un aspect noir très brillant.

Le jais est une variété du lignite et se rattache à la classification des charbons humiques, très riches en matières organiques (Foucault et Raoult, 2005). Il est constitué de débris et de tissus cellulaires du bois de la famille des coniferes. Sa formation en milieu anaérobie dans des eaux stagnantes fait que ce matériau est extrêmement riche en matière organique et en hydrocarbures. La présence d'hydrocarbures lui confere une stabilité et une densité qui permettent de le travailler et de le polir aisément. Le fragment examiné ici est relativement bien conservé et ne se désagrège pas en feuillets comme cela est parfois le cas.

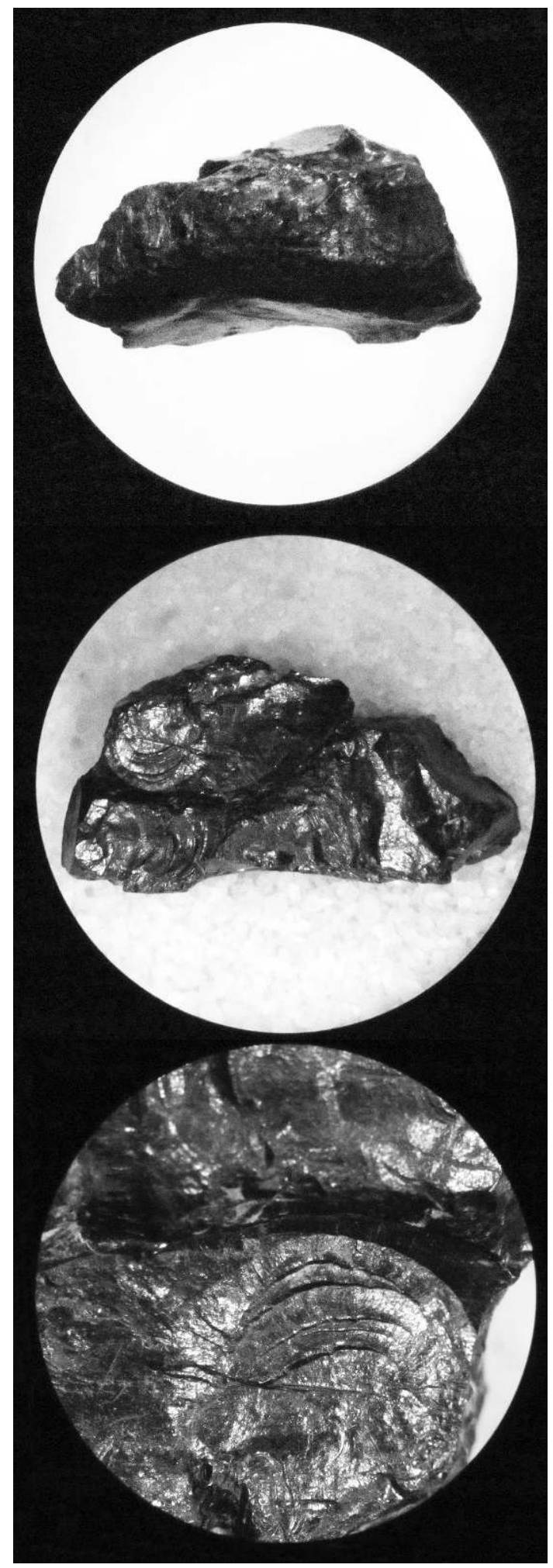

Figure 17 : Le fragment de jais : à la loupe binoculaire $\times 8$ (en haut et au milieu); détail de la cassure conchoïdale à la loupe binoculaire $\times 20$ (en bas).

Figure 17: The piece of jet: under binocular X 8 (at the top and in the middle); detail of conchoidal break under binocular X 20 (at the bottom). 
Exploité depuis la Préhistoire, le jais est principalement utilisé à l'âge du Fer en contexte funéraire, sous forme de perles pour des colliers ou bracelets; il est relativement fréquent dans le domaine hallstattien. Pour la période laténienne, celui-ci a tendance à diminuer, mais se rencontre de nouveau (et exclusivement?) en contexte funéraire (Baron, 2012). Sous sa forme brute, il est uniquement connu dans la tombe princière de Reinheim, en association avec un fragment d'ambre (Echt, 1999). La présence de cet objet a été interprétée comme une amulette "symbolique " possédant des vertus protectrices (Echt, 1999). En contexte domestique et pour la période laténienne, les fragments de jais bruts n'ont à ce jour pas encore été recensés. Leur identification, il est vrai, peut être ignorée. Par contre pour la période romaine, on assiste à une utilisation plus massive de ce matériau, à une échelle quasi-industrielle qui se traduit par une diffusion dans tout le monde romain (Allason-Jones et Jones, 1994; Hagen, 1937; Watts, 1996)

Le fragment découvert à Nantes permet de proposer deux utilisations possibles : soit il s'agit d'un déchet de fabrication d'un objet (cependant, étant donné la taille de l'objet et l'absence de trace de taille, cela parait peu probable), soit il s'agit d'un matériau utilisé comme "amulette " ou pierre de protection. Rappelons que selon Pline, ces roches possèdent des vertus magico-religieuses qui protègent contre " le mauvais œeil " (Pline l'Ancien, Histoire naturelle, livre XXXVI, \$141).

Bien que le fragment de Nantes n'ait pu être analysé, l'absence de gisement de jais à l'échelle régionale implique qu'il ait été importé. Des gisements sont connus un peu partout en Europe - en France, en Angleterre, en Allemagne, en Pologne, au Danemark ou en Ecosse (Marshall, 1975; Weller et Wert, 1993) - mais peu d'entre eux ont pu être identifiés comme ayant été exploités par les populations anciennes, à l'exception de la source anglaise de Whitby dans le Yorkshire, où des travaux ont montré une exploitation sur la longue durée (Watts, 1996; Allason-Jones et Jones, 2001). Cependant, cette source n'a pas été la seule exploitée puisque l'analyse chimique de certains objets archéologiques montre des compositions différentes de celle identifiée dans le Yorkshire. Il faut donc envisager d'autres provenances. Des gisements de jais ont ainsi été identifiés dans le nord de l'Espagne (Asturies), où ils ont été exploités au moins à partir du Moyen Âge, mais sans doute dès la période romaine (Baron, 2012).

La présence de ce fragment brut est pour la période de La Tène finale, atypique et exceptionnelle. En effet, peu de fragments bruts de jais sont connus en contexte d'habitat pour cette période. Il se peut que ce fragment ait eu une fonction apotropaïque, ce qui constituerait un témoignage rare de ces pratiques en contexte gaulois.

\section{LE BOIS-HUE DANS SON CONTEXTE LOCAL : LES OCCUPATIONS GAULOISES À LA CONFLUENCE DE L'ERDRE ET DE LA LOIRE}

\section{Lâge du Fer en Pays nantais}

Jusqu’à une date récente, l'âge du Fer de Loire-Atlantique était très mal documenté. À l'exception de la presqu'île guérandaise et des travaux bénévoles de $\mathrm{M}$. Tessier sur le littoral du Pays de Retz, l'archéologie n'a que peu accompagné les aménagements pourtant considérables à l'œuvre dans le département (Bouvet, 2002). La situation a changé depuis une quinzaine d'années, avec la mise au jour, presque exclusivement dans le cadre de prescription d'archéologie préventive, d'occupations attribuables aux deux âges du Fer.

Tributaire de l'urbanisation et de l'implantation des infrastructures, cette archéologie a considérablement renouvelé nos connaissances sur ce territoire, en se concentrant naturellement autour de Nantes et plus largement le long de la Loire et sur le littoral, c'est-à-dire là où la pression foncière est la plus forte.

L'occupation de l'âge du Fer de l'agglomération nantaise, longtemps sous-documentée, commence aujourd'hui à se dessiner. On signalera parmi les récentes découvertes, celles de nécropoles du Premier et du début du Second âge du Fer à Rezé sur les sites de La Forêt 3 (Sélèque, 2012) et de La Jaguère (fouille : P. Rieunier) et à Bagatelle à Saint-Herblain (Prêtre, 2014). À Bouguenais, la fouille programmée dirigée par J. Rémy (doctorante Université de Tours) a permis d'attribuer au Premier âge du Fer la fortification de La Sangle (Rémy, 2013; 2016). À l'extrémité de ce promontoire, de récents sondages nous ont permis d'identifier des niveaux de La Tène finale, antérieurs à la probable motte féodale (Routhiau, 2016). D'autres fouilles ont eu lieu à proximité de Nantes qui concernent pour certaines le Premier âge du Fer, telle celle du site du Civerda au Bignon (Viau, 2008), et pour d'autres des fermes laténiennes; on citera notamment les sites des Ténauderies à Aigrefeuilles-sur-Maine (Toron, 2016) et du Plessis au Loroux-Bottereau (fouille G. Verrier, Archeodunum).

Aujourd'hui, à l'exception de dragages anciens en Loire qui ont remonté du mobilier de l'âge du Fer, aucun niveau gaulois n'a jamais été perçu dans le centre de Nantes. En revanche, le territoire dans lequel s'implante le site du Bois Hue, entre Erdre et Loire a révélé une forte densité d'établissements gaulois mis au jour à l'occasion de nombreux diagnostics et fouilles. 


\section{Les sites de l'âge du Fer de l'interfluve Erdre-Loire}

\section{Les données paléo-environnementales}

La vallée de l'Erdre et ses différentes zones humides d'aval ont fait l'objet de plusieurs études par L. Visset et son équipe de l'université de Nantes. Ainsi la thèse de palynologie soutenue par A. Ouguerram (2002) et portant précisément sur la vallée de l'Erdre, permet d'esquisser un cadre général de la végétation de la vallée à l'âge du Fer.

La période du Subatlantique est marquée, à la fin du Second âge du Fer (Ouguerram, 2002), par « une large ouverture au sein de l'ensemble forestier, à mettre en relation avec un défrichement intense, en vue de l'exploitation agro-pastorale " (Ouguerram et Visset, 2001, p. 197). Létude d'une tourbière située quelques kilomètres au nord du site, montre une importante céréaliculture, mais aussi la présence de poacées qui témoignent de l'essor de l'élevage (Ouguerram, 2002; Ouguerram et Visset, 2001).

Ces données sont cohérentes avec la mise en évidence, d'un point de vue forestier et à partir des paléo-restes découverts au Clouët à Carquefou, de l'exploitation de cépées au sein de paysages largement ouverts (Bernard, 2005).

\section{Aperçu général des occupations gauloises}

Cette ouverture du milieu se marque archéologiquement par de nombreuses découvertes de sites de l'âge du Fer sur les communes de Nantes, Carquefou, Sainte-Luce-sur-Loire, Thouaré-sur-Loire et Mauves-sur-Loire (fig. 18).

En effet, l'interfluve formé par l'Erdre et la Loire en amont de leur confluence, est bien documenté pour l'âge du Fer avec, à ce jour, au moins une douzaine de sites ou indices de site relevant de cette chronologie. Le site du Clouët à Carquefou (Le Goff, 2003), auquel il faut désormais associer

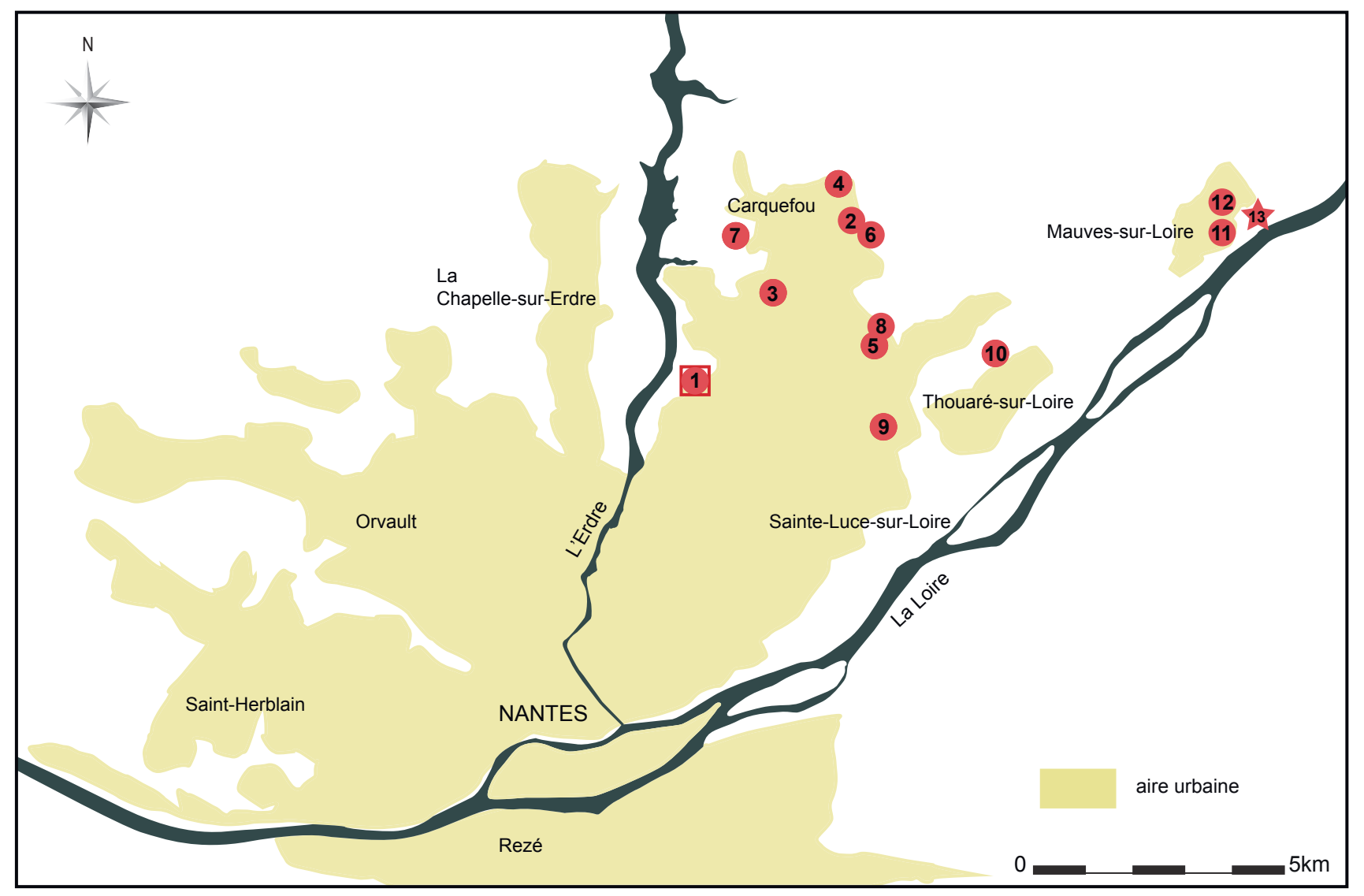

Figure 18 : Cartographie des sites de l'âge du Fer entre Erdre et Loire (A. Levillayer). 1 : Nantes, Le Bois Hue; 2 : Carquefou, Le Bois SaintLys (Bellanger, 1991); 3 : Carquefou, La Bréchetière (Vacher, 1992); 4 : Carquefou, Le Clouët - Les Mazères (Le Goff, 1998; 2003 ); 5 : Carquefou, La Haute Forêt (Valais, 2012); 6 : Carquefou, ZAC du Clouët (fouille : C. Vasnier) ; 7 : Carquefou, La Fleuriaye - Les Petites Renaudières (Hervé-Monteil, 2015); 8 : Carquefou, Cufroid (Jemin, 2016); 9 : Sainte-Luce-sur-Loire, Les Maisons Neuves 2 (Nauleau, 2010) ; 10 : Thouaré-sur-Loire, ZAC des Deux Ruisseaux (Forré, 2008) ; 11 : Mauves-sur-Loire, rue de la Prime (Hervé-Monteil, 2009); 12 : Mauves-sur-Loire, ZAC Pontereau-Piletière (Brodeur, 2016); 13 : Mauves-sur-Loire, sanctuaire de Vieille-Cour (Monteil et al., 2009). Figure 18: Iron Age settlements between the Erdre and the Loire. 
celui du Bois Hue, montre que les plateaux qui dominent l'Erdre sont exploités dès le IV ${ }^{\mathrm{e}} \mathrm{s}$. av. n. è. La récente découverte d'une occupation dont l'origine est à situer au moins à La Tène ancienne, à La Fleuriaye à Carquefou, sur le site des Petites Renaudières (Hervé-Monteil, 2015), ajoute encore au tableau d'un espace dont l'exploitation semble relativement précoce dans le Second âge du Fer. Sur la ZAC de La Haute Forêt, toujours à Carquefou, une partie d'enclos fondé à la même époque a été mise au jour lors d'une fouille réalisée par A. Valais (2012).

Qui plus est, des traces d'occupations antérieures, attribuables au Bronze final et au Premier âge du Fer ont été mises en évidence au Clouët à Carquefou sous la forme de deux enclos circulaires (habitat ou sépultures?) fouillés par C. Vasnier (Archeodunum), et à Mauves-sur-Loire, rue de la Prime, avec un sol associé à une structure de chauffe (HervéMonteil, 2009). À Sainte-Luce-sur-Loire, le diagnostic réalisé à La Maison Neuve a permis de montrer l'implantation d'un enclos d'habitat entre la fin du Premier Âge du Fer et le début du Second (Nauleau, 2010).

Si le secteur semble donc déjà fortement occupé dès La Tène ancienne, c'est dans le courant du $\mathrm{II}^{\mathrm{e}} \mathrm{s}$. av. n. è. qu'on observe une densification de l'occupation. Elle se traduit par la fondation de nouveaux établissements ruraux : celle du site de Cufroid à Carquefou est attribuée à La Tène C2-D1 (Jemin, 2016), alors que les sites de La Bréchetière (Vacher, 1992) et du Bois Saint Lys (Bellanger, 1991), toujours à Carquefou, sont vraisemblablement occupés à partir du début du $\mathrm{I}^{\mathrm{er}}$ siècle av. n. è. À Sainte-Luce et à Thouaré, ce sont de vastes systèmes fossoyés qui peuvent être attribués à cet horizon chronologique, et qui sont identifiés à un système parcellaire et à des chemins (Forré, 2008; Nauleau, 2010). Ces créations ne s’accompagnent pas pour autant d'un abandon des sites précédemment occupés, puisque Le Bois Hue, Le Clouët et Les Petites Renaudières perdurent au moins jusqu'au début du $\mathrm{I}^{\text {er }}$ s. av. n. è. En fait, seul le site de La Haute Forêt est abandonné à une date plus haute, sans doute au III siècle (Valais, 2012).

À ces sites qui correspondent à un réseau de fermes, s'ajoute la découverte de niveaux protohistoriques sous le sanctuaire antique de Vieille-Cour à Mauves-sur-Loire. S'il n'est pas possible à l'heure actuelle de définir la nature exacte de ces niveaux pour l'âge du Fer (sanctuaire?), du mobilier contemporain de la fondation du Bois Hue y a été identifié (Monteil et al., 2009, p. 176).

La question du devenir des sites montre des situations contrastées. Les sites du Bois Hue, du Clouët et de Cufroid semblent disparaître assez tôt dans le $\mathrm{I}^{\mathrm{er}}$ siècle. Pour autant, ainsi que le montrent les fouilles de Saint-Joseph de Porterie, cela se traduit par un déplacement de l'occupation de l'ordre de quelques centaines de mètres (Devals, 2010). D'autres sites connaissent au contraire une occupation plus tardive, à l'image du site de La Bréchetière dont une partie du mobilier témoigne d'un faciès tardif (La Tène D2 ?) et où, à nouveau, la découverte de fossés antiques semble plaider pour un déplacement de l'habitat à proximité durant le Haut Empire (Vacher, 1992). Un récent diagnostic réalisé à Mauves-surLoire montre que l'origine de l'agglomération antique dont participe le sanctuaire de Vieille-Cour précédemment évoqué - remonte peut-être à La Tène $\mathrm{D} 2$, période pour laquelle un "bruit de fond " a été perçu (Brodeur, 2016).

Comment expliquer cette abondance de sites sur ces $30 \mathrm{~km}^{2}$ et durant au moins quatre siècles? L'opportunité de travaux d'archéologie préventive, sous la forme notamment de diagnostics de grande ampleur, explique sans doute en partie la vision d'un espace densément occupé. Ainsi on peut souligner que les terrains de Saint-Joseph de Porterie ou de Carquefou étaient parmi les derniers de la métropole à présenter de vastes surfaces encore peu urbanisées. Pour autant, même si seule une étude géostatistique permettrait de l'affirmer, les autres secteurs périphériques de l'agglomération ne semblent pas livrer une occupation contemporaine aussi dense.

En se gardant de tout déterminisme géographique, l'espace considéré ici peut apparaître comme particulièrement propice. À immédiate proximité de l'Erdre, cours d'eau d'importance qui le relie au nord du territoire namnète, à proximité d'une voie de communication majeure qu'est la Loire, ce secteur offrait sans doute, en particulier sur les plateaux et le haut des coteaux, des terrains particulièrement propices à la culture et à l'élevage. On peut aussi s'interroger quant à la place de ce terroir, en amont du franchissement de la Loire que constitue le site de Nantes - ce dont témoignent son nom antique de Condevicnum et les découvertes faites en Loire (Levillayer, 2013) - et sur l'implantation des sites de part et d'autre d'une ligne de crête qui s'étire depuis la confluence vers le nord-est (fig. 2).

Ce rôle d'interface se reflète au travers du faciès mobilier des sites, notamment par la présence systématique d'amphores vinaires dont le transport via la Loire ne doit pas être négligé (Bouvier, 2000). C'est aussi très probablement par le fleuve qu'est remonté le sel depuis le littoral du Pays de Retz. Ce produit, dont la présence sur les sites de consommation est de plus en plus fréquemment relevée (Daire, 2003), arrive au Bois Hue dès le début de son occupation. Il témoigne des relations entre la façade littorale productrice et son arrière-pays consommateur, voire peut-être redistributeur. Des vases à lèvres en gouttière, caractéristiques du Pays de Retz, illustrent également ces contacts; on les retrouve d'ailleurs ponctuellement jusqu'à Ancenis (Viau, 2010, fig. 127). Les sites de l'interfluve Erdre-Loire entretiennent également des liens avec des régions plus éloignées de Gaule, ainsi qu'en atteste la découverte de céramiques de 
type « Besançon » originaires de Gaule centrale (Lallemand et Tuffreau-Libre, 2005; Tyers, 2001). À nouveau le fleuve joue un rôle majeur dans l'arrivée de ces productions (et surtout des produits qu'elles contenaient) qu'on retrouve systématiquement sur les sites voisins de la Bréchetière et du Clouët, et même - malgré sa modestie - au Bois SaintLys (fig. 19). Ce territoire constitue d'ailleurs la zone la plus occidentale de diffusion de ces céramiques, à l'exclusion de quelques exemplaires découverts autour de Guérande et Pornic notamment (Levillayer, en préparation).

Distants d'1 à $2 \mathrm{~km}$ les uns des autres, ces sites étaient vraisemblablement, et de façon logique (Le Goff, 2009, p. 97-99), connectés les uns aux autres. On entrevoit ce réseau à travers la découverte du chemin du Bois Hue qui, descendant du plateau, oblique à proximité du site. Sans vouloir en faire un axe majeur, et pour autant qu'il soit possible d'argumenter à partir du faible linéaire étudié, ce chemin semble suivre le plateau en remontant vers le nord-est, se dirigeant ainsi vers les sites déjà évoqués. Bien sûr, les arguments chronologiques font défaut pour établir sa data- tion mais la marque qu'il a laissée à l'époque antique semble plaider pour qu'il ait fonctionné à la fin de l'époque gauloise.

Pour autant, les différents sites évoqués ne se ressemblent pas. Les sites du Clouët et surtout celui du Bois Hue, présentent des caractéristiques structurelles (superficie, densité et durée de l'occupation) qui les distinguent des autres fermes, et donnent l'image de sites au statut privilégié.

\section{Le Bois-Hue : un établissement gaulois important}

Marqué par la stabilité de son enclos principal, l'établissement du Bois Hue livre une stratigraphie et un ensemble céramique conséquents pour la région.

Fondé à La Tène B (horizon 1), sans doute quelques décennies avant le site du Clouët, le site du Bois Hue est marqué par la stabilité de sa limite fossoyée qui perdurera plus de deux siècles, sans connaitre de restructuration dans la partie que nous avons fouillée.

Cette apparition à la fin du IV siècle est intéressante car les sites fondés à cette date sont moins nombreux que pour les périodes suivantes (aux $\mathrm{III}^{\mathrm{e}}$ et $\mathrm{II}^{\mathrm{e}}$ siècles av. n. è.
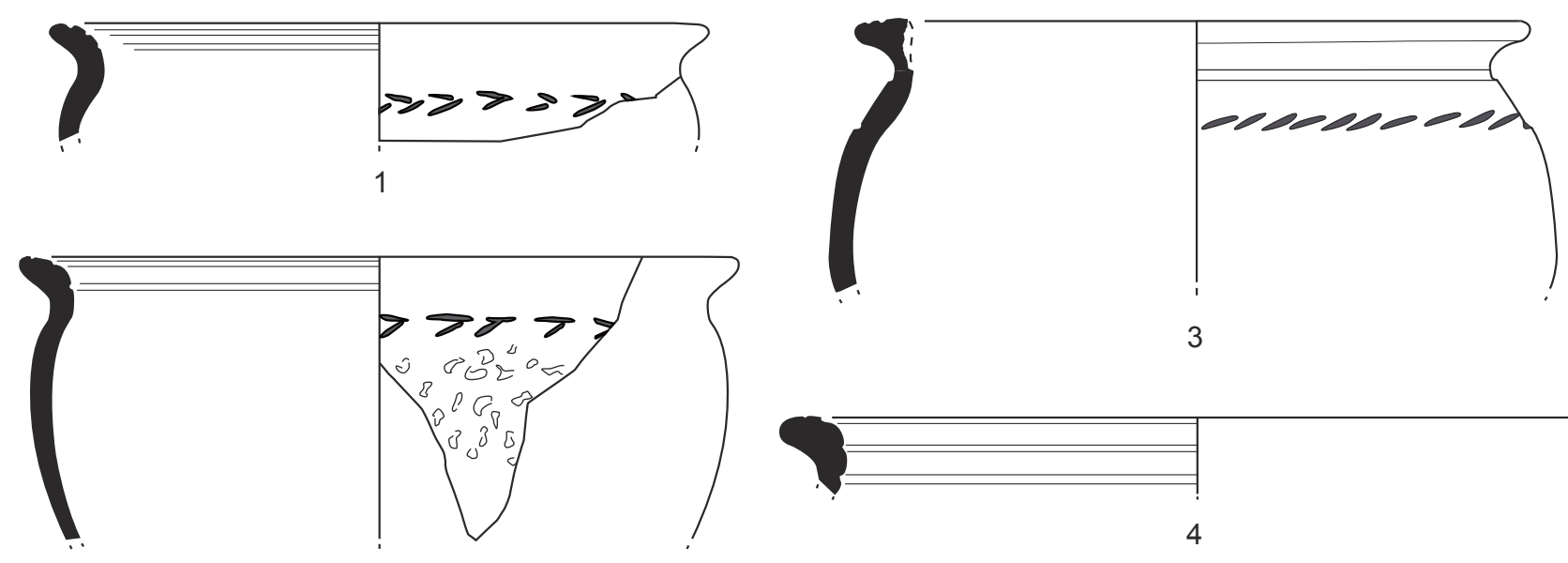

2
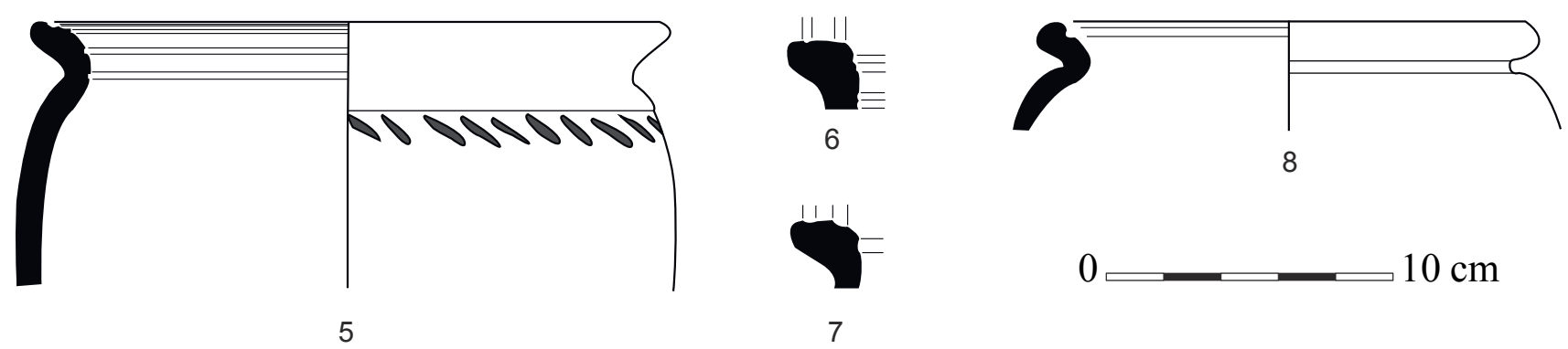

8

Figure 19 : Quelques vases de «type Besançon " découverts sur les sites nantais. 1 à 4 : Nantes, Le Bois Hue; 5 à 7 : Carquefou, La Bréchetière (d'apr. Vacher, 1992); 8 : Carquefou, Le Clouët (d'après Le Goff, 1998).

Figure 19: Some "type Besançon" potteries discovered around Nantes. 
surtout), particulièrement dans la région (Blancquaert et al., 2009, fig. 7). En effet, peu de sites de La Tène B sont connus régionalement : on peut citer pour les principaux, en Loire-Atlantique, La Galonnière (Bellanger, 2000) et La Gravouillerie (Vacher, 2000) à Saint-Philbert-de-Grandlieu, et La Colleraye à Savenaye (Sélèque, 2013). Quelques sites du nord de la Vendée sont fondés à cette époque, dont Les Ecobuts à La Bruffière (Nillesse, 2005) et peut-être La Sangle à La Verrie (Pétorin, 2001). Il semble que plusieurs de ces enclos contemporains du Bois Hue adoptent, comme lui, un plan curvilinéaire (Levillayer, sous presse).

En Bretagne en revanche, les sites occupés depuis La Tène ancienne et perdurant, comme celui du Bois Hue, jusqu'à La Tène finale sont plus nombreux, à l'image des sites du Boisanne à Plouër-sur-Rance (Menez, 1996). Dans le Centre-Ouest, quelques établissements connaissent une occupation dès La Tène ancienne qui perdurera ensuite, à l'image du site des Ormeaux à Angoulins en CharenteMaritime (Maguer et al., 2009a). Reste que là encore, on note une sous-représentation de cette période (Maguer et al., 2009b, p. 425-426). Celle-ci peut d'ailleurs être généralisée à de très nombreuses régions de Gaule (Malrain et al., 2013). Cette déficience est parfois expliquée par la structuration de certains de ces sites qui pourraient être non enclos, à l'image du site de Toutejoie à Gétigné en Loire-Atlantique (Viau, 2014), le site du Bois Hue se distinguant alors, notamment, par les dimensions de son fossé d'enclos.

Le site ne connaît pas de hiatus dans son occupation protohistorique, même s'il est difficile de cerner le faciès céramique de La Tène C1, celui-ci ayant heureusement pu être défini grâce aux données stratigraphiques.

L'étude céramique et amphorique des derniers niveaux du comblement du fossé d'enclos, les plus riches en mobilier, permet d'établir que le site est abandonné au plus tard à La Tène D1, sans doute au tournant des $\mathrm{II}^{\mathrm{e}}$ et I $\mathrm{I}^{\mathrm{er}}$ siècles av. n. è.

La base économique agricole du site ne laisse guère de doutes, ainsi qu'en témoigne la présence de greniers ou encore de meules destinées principalement à la mouture du grain, quoique certaines aient pu avoir un usage artisanal (broyage de colorant?). Cet artisanat apparaît, comme sur la quasi-totalité des sites gaulois, ponctuel et pratiqué dans un cadre essentiellement familial. Le tissage est attesté par quelques pesons. Le travail des métaux est également représenté dans sa diversité, avec des scories de réduction du fer, rarement rencontrées en contexte d'habitat, et une scorie de bronze, sans doute résiduelle (identification : Y. Bière). Les quantités sont toutefois extrêmement modestes.

Pourtant, les dimensions du fossé, l'abondance - relative - d'amphores posaient la question du statut socio-économique du site dont la définition a été au cœur de nos problématiques de fouille. Différents critères doivent être pris en compte, dans la mesure bien sûr où l'archéologie peut le définir (Malrain et Blancquaert, 2009; Nillesse, 2003), surtout au regard d'une fouille ici non exhaustive.

Dans sa partie accessible, l'enclos adopte un plan curvilinéaire à fossé massif. Ce type de plan n'est pas si fréquent dans le corpus régional (fig. 20). Parmi les plans les plus proches, on peut citer celui de Chanzeaux à La Morinière dans le Maine-et-Loire (Le Goff, 1999), qui est toutefois trois fois moins vaste que celui de Nantes! Les sites géographiquement les plus proches, ceux du Clouët et de La Galonnière, adoptent des formes rectilignes trapézoïdales, d'autres sites montrant des plans curvilignes (premières phases de La Sangle à La Verrie, et des Natteries à Cholet). Ce plan, signalons-le à nouveau, ne connaîtra pas d'évolutions pendant plus de deux siècles, à l'inverse de la situation la plus courante, qui voit notamment en de nombreux cas, passer l'enclos d'une forme curviligne à des tracés plus rectilignes au cours de La Tène moyenne et finale (Maguer, 2000 ; Maguer et al., 2009b). Au Bois Hue, le site reste, pour sa partie orientale, dans les limites de son tracé initial. Il est difficile d'établir la superficie totale du site. Dégagé sur $3505 \mathrm{~m}^{2}$, il est probable (mais hypothétique) que la surface enclose maximale représente entre 5000 et $7000 \mathrm{~m}^{2}$.

Pourtant, nous l'avons souligné à plusieurs reprises, le fossé apparaît comme relativement massif, pouvant avoisiner $4 \mathrm{~m}$ de largeur et dépassant les 2,6 $\mathrm{m}$ de profondeur. Si ces dimensions sont loin de celles atteintes par les fossés des phases fortifiées des habitats aristocratiques (Maguer, 2000; Menez, 2008), aucune fonction défensive ne pouvant être attribuée au site du Bois Hue, elles dépassent pourtant largement celles constatées régionalement. À La Bréchetière par exemple, les fossés III, $V$ et IX atteignent au maximum 1,5 m de profondeur (Vacher, 1992).

Selon Y. Menez (2008, p. 16), seuls $15 \%$ des sites enclos présentent des fossés de plus de $2 \mathrm{~m}$ de profondeur ${ }^{3}$. L'étude réalisée à l'occasion du colloque de Chauvigny montre des dimensions modestes, avec des profondeurs moyennes de $1,47 \mathrm{~m}$, la proportion de fossés dépassant les $2 \mathrm{~m}$ n'étant que de $16 \%$ (Maguer et al., 2009a, p. 430).

Parmi les sites présentant un fossé aussi profond, et aussi large, on trouve le site du Pinier à Beaupréau (Maine-etLoire) où se pose également la question du statut social des habitants (Levillayer et Prigent, 2010). À La Galonnière à Saint-Philbert-de-Grandlieu, le fossé septentrional adopte aussi une grande largeur mais pas une aussi grande profondeur. On peut aussi mentionner deux sites, diagnostiqués mais malheureusement non fouillés, qui présentent des fossés massifs : l'Ecobue à Mortagne-sur-Sèvre en Vendée avec

3. $10 \%$ des sites présentent un fossé profond de 2 à 2,49 $\mathrm{m}$, les $5 \%$ restant incluant les très larges fossés (de 6 à $10 \mathrm{~m}$ ) des résidences aristocratiques. 
Figure 20 : Plans comparés des sites régionaux contemporains de la fondation du Bois Hue (La Tène B2 et C1). Figure 20: Different plans of contemporaneous regional settlements to the foundation of Le Bois Hue (La Tène B 2 et C1).

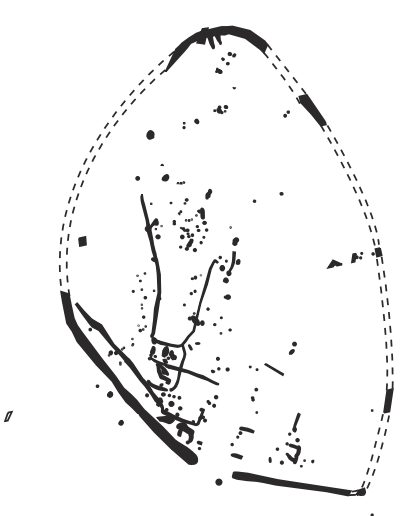

La Verrie, La Sangle (85) d'ap. Pétorin, 2001

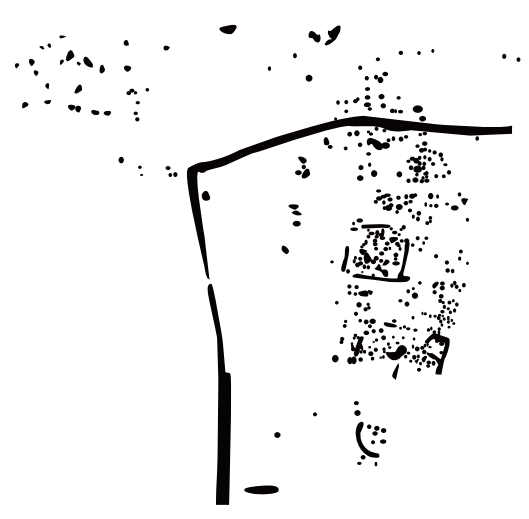

Carquefou, Le Clouët (44) d'ap. Le Goff, 1998

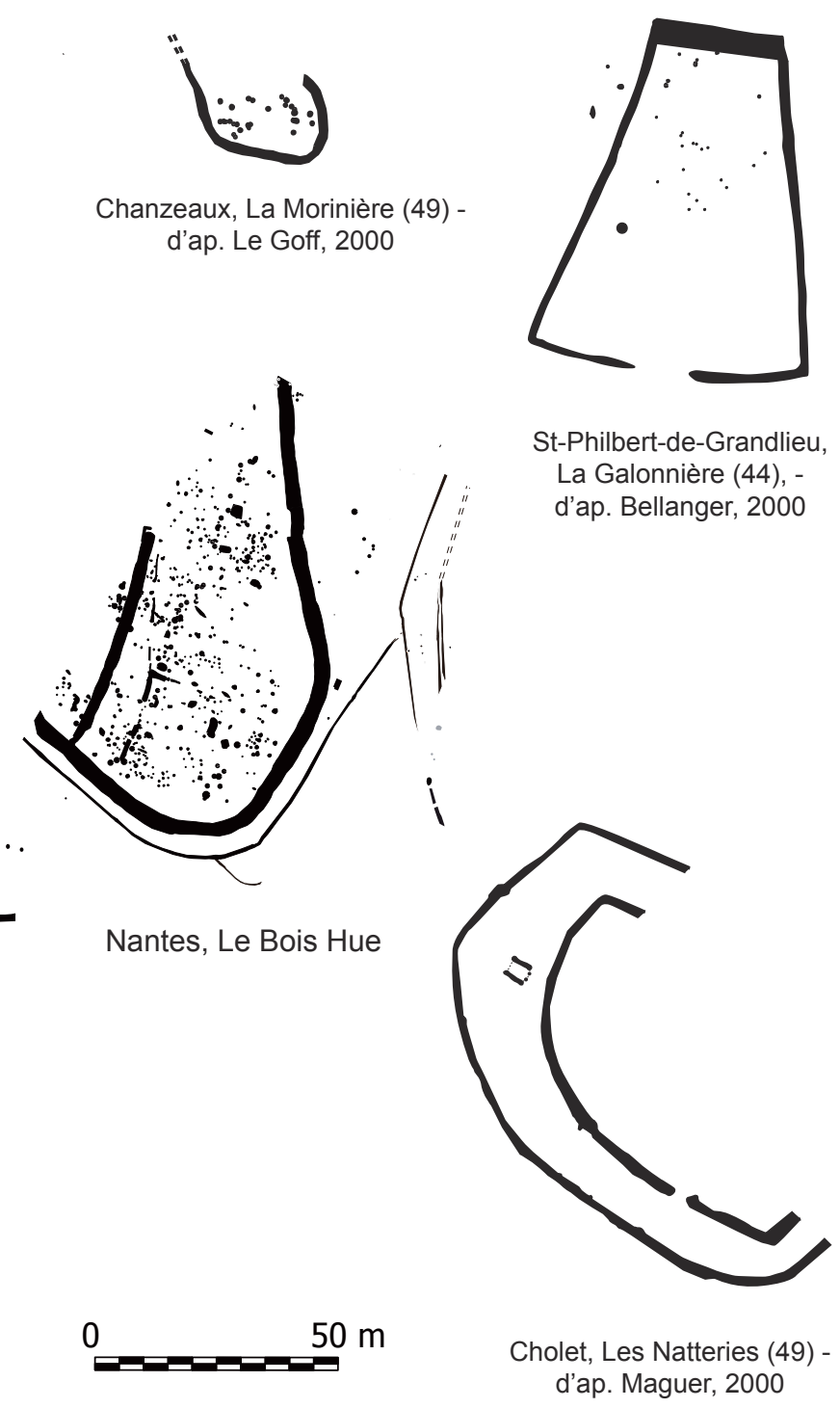

SO-NE, orientation majoritaire des bâtiments, qui correspond à celle de l'enclos : peuvent y être rattachés les bâtiments E1, E2, E4, E5, E6, E11, E12, E13, E14, E15, E18, E19 et E20 qui s'alignent sur le fossé de partition. Quatre bâtiments présentent une orientation N-S différente; il s'agit de E3, E7, E8 et E9. Il est donc en l'état impossible de distinguer un phasage qui correspondrait peu ou prou à un lotissement planifié qui, avouons-le, ne semble pas avoir prévalu sur le site.

Pour aborder la question du statut du site, un rapide retour sur le mobilier s'impose. Le lot céramique, compte tenu d'une fouille presque intégrale du fossé d'enclos, n'apparaît pas comme extraordinaire, ni par sa quantité (2500 tessons environ), ni par sa qualité (rareté des décors, des céramiques fines...). La présence d'amphores est intéressante. Sa quantité, bien que significative (365 tessons pour un NMI de 18 ), reste très loin des quantités relevées sur les sites dont le divergentes sur le site (fig. 10). D'une part, une orientation 
statut aristocratique est avéré (2 178 aux Natteries à Cholet, 3135 au Chemin Chevaleret à Echiré, 3442 aux Genâts à Fontenay-le-Comte). Si d'autres sites comme celui de La Haute Couperie à La Roche-sur-Yon (Vendée), également fouillé de manière incomplète, livre plus de 1500 tessons (Nillesse 2004), le site du Bois Hue s'inscrit dans une fourchette haute pour la région, qui témoigne d'un certain pouvoir économique. L'enquête de Chauvigny estime à 17,8\% le nombre de sites à amphores (Blancquaert et al., 2009, p. 17). Ainsi, à l'échelle de la façade atlantique, entre Loire et Dordogne, seuls huit sites ont un NMI supérieur à 10 (Maguer et al., 2009b, p. 446).

Mais plus encore que le nombre (qui demande à être lu au vu de la surface étudiée), c'est le faciès amphorique qui attire l'attention. En effet, on note sa précocité et son homogénéité, qui le rapprochent des ensembles des sites aristocratiques mentionnés précédemment (Les Natteries, Les Genâts, Le Chemin Chevaleret...), où la consommation de vin est mise en relation avec des pratiques collectives (Lemaitre et Sanchez, 2009, p. 345-348). Ce même faciès est également relevé sur quelques rares autres sites comme celui des Rochereaux à Migné-Auxances dans la Vienne (Toledo I Mur et Pernot, 2008) qui, bien que modeste, a livré un atelier de fabrication monétaire...

Parmi les autres signes ostentatoires de richesse tels qu'ils ont été modélisés par Y. Menez (2008), on note l'absence des vestiges significatifs que sont l'art, l'armement, la chasse ou encore une alimentation de qualité. Cette absence n'est toutefois pas porteuse d'informations probantes dans la mesure où les sols particulièrement acides mettent à mal la conservation des métaux ferreux et de l'os.

\section{Conclusion}

La fouille du site du Bois Hue a fait émerger pour la première fois une occupation structurée gauloise à Nantes. Bien sûr, elle ne peut être reliée à une éventuelle occupation de l'âge du Fer à l'emplacement de la future ville au confluent de l'Erdre et de la Loire. Mise en perspective des nombreux autres sites qui émergent sur quelques dizaines de kilomètres carrés, elle permet par contre aujourd'hui de proposer une première lecture d'un territoire très tôt - et sans discontinuité - occupé à l'âge du Fer. Corroborant ce qui avait été perçu par les études palynologiques, ce réseau d'établissements gaulois semble profiter d'une position qui lui permet de présenter un faciès mobilier homogène, témoignant de relations commerciales privilégiées sous-tendues par une vraisemblable richesse agricole. Ces premiers éléments

4. Même si, faut-il le rappeler, une partie seulement du site a été fouillée rendent aujourd'hui nécessaires leur exploration future sous l'angle de leur mise en réseau.

\section{Bibliographie}

Allason-Jones L. et Jones D.-M., 1994 - « Jet and other materials in Roman artefact studies, Museum Notes ", Archaeologia Aeliana, $5^{\text {th }}$ serie, vol. XXII, The Society of Antiquaries of New-Castle-Upon-Tyne, p. 263-272.

Allason-Jones L. et Jones D.M., 2001 - «Identification of jet artefacts by reflected light microscopy ", European Journal of Archaeology, vol. 4, 2, London, 2001, p. 233-251.

Arthuis R. et Nauleau J.-F., avec la coll. de Goubert E., BARbier-Pain D. et BAudoin V., 2015 - «Reconstitution paléogéographique de la vallée de la Loire à Nantes depuis 8000 ans ", in Arthuis R. et Monteil M. (dir.), Archéologie de la Basse-Loire, Rennes, Presses Universitaires de Rennes, p. 23-43.

Baron A., 2012 - Provenance et circulation des objets en roches noires ("lignite ") à l'âge du Fer en Europe celtique (viiie-ier s. av. J.-C.), BAR International Series, 2453, Oxford, 589 p.

Bellanger P., 1991 - Carquefou (44). Le Bois Saint Lys. Rapport de sondage, Nantes, AFAN-SRA Pays de la Loire, 14 p.

Bellanger P., 2000 - Saint-Philbert-de-Grandlieu, La Galonnière (déviation de Pied-Pain-RD 117). Rapport de fouille préventive, AFAN-SRA Pays de la Loire, 45 p.

Bernard V., 2005 - "Vers une maîtrise des ressources forestières? Dendro-typologie des bois d'architecture domestique employés dans le nord-ouest de la France pendant l'âge du Fer (vi ${ }^{\mathrm{e}}-\mathrm{I}^{\mathrm{er}}$ s. av. J.-C.) ", in Buchsenschutz O. et Mordant C. (dir.). Architectures protohistoriques en Europe occidentale du Néolithique final à l'âge du Fer, Actes du $127^{\mathrm{e}}$ congrès national des sociétés historiques et scientifiques, Nancy, 15-20 avril 2002, Paris, Éditions du CTHS, p. 13-23.

Blaizot F., (dir.), 2009 - « Pratiques et espaces funéraires de la Gaule durant l'Antiquité », Gallia, 66.1, 385 p.

Blancquaert G., Lorho T., Malrain F. et Menez Y., 2009 "Bilan et perspectives de recherches sur les sites ruraux au second âge du Fer ", in Bertrand I., Duval A., Gomez de Soto J. et Maguer P. (dir.). Habitats et paysages ruraux en Gaule et regards sur d'autres régions du monde celtique. Actes du $\mathrm{XXXI}^{\mathrm{e}}$ colloque de l'AFEAF, Chauvigny, 2007. Mémoires de l'APC, XXXIV, p. 5-23.

Bossard S., Guillier G., Lepaumier H. et Levillayer A., à paraître - Les architectures des structures de stockage alimentaire à l'âge du Fer dans l'Ouest de la France : choix techniques ou culturels?, Actes du XVe colloque de l'AFEAF de Rennes, mai 2016.

Bouvet J.-P., 2002 - «Aperçu sur les Âges du Fer dans le département de la Loire-Atlantique ", Bulletin de la Société Nantaise de Préhistoire, $\mathrm{n}^{\circ}$ 399, p. 2-5. 
Bouvier M., 2000 - « Les fleuves, vecteurs du transport du vin dans l'Antiquité ", in Bedon R. et Malissard A. (éd.). La Loire et les fleuves de la Gaule romaine et des régions voisines, Caesarodunum, XXIII-XXIV, p. 297-315.

Brodeur J. (dir.), 2016 - Mauves-sur-Loire (Loire-Atlantique), ZAC Pontereau-Piletière, tranche 2. Rapport Final d'Opération de diagnostic archéologique, Nantes, INRAP-SRA Pays de la Loire, $89 \mathrm{p}$.

Buchsenschutz O., 2005 - «Du comparatisme à la théorie architecturale ", in Buchsenschutz O. et Mordant C. (dir.). Architectures protohistoriques en Europe occidentale du Néolithique final à l'âge du Fer. Actes des congrès nationaux des sociétés historiques et scientifiques, $127^{\mathrm{e}}$ congrès, Nancy, 15-20 avril 2002, Éditions du CTHS, Paris, p. 49-63.

Buchsenschutz O., Jaccottey L., Jodry F. et Blanchard J.-L. (dir.), 2011 - Évolution typologique et technique des meules du Néolithique à l'an mille sur le territoire français, Actes de la table ronde de Saint-Julien-sur-Garonne, du 2 au 4 octobre 2009, $23^{\mathrm{e}}$ supplément Aquitania, 487 p.

Cornec J., Le Goff E., Le Guévellou J., Levillayer A., Moreau C., Mortreau M. et Thébaud S., à paraître - « La céramique du $\mathrm{VI}^{\mathrm{e}}$ au I ${ }^{\mathrm{er}}$ s. av. n. è. en Pays de la Loire : évolution des formes, des décors et mobiliers associés ", in Menez Y. (dir.). Céramiques gauloises d'Armorique, Rennes, Presses Universitaire de Rennes.

DAIRE M.-Y., 1992 - Les céramiques armoricaines de la fin de l'Âge $d u$ Fer, Rennes, Travaux du laboratoire d'anthropologie de Rennes, 316 p.

Daire M.-Y., 2003 - Le sel des Gaulois, Paris, Errance, 152 p.

Dechezleprêtre T., Cousyn P., Paez-Rezende L. et Rougier R., 2000 - "Architecture des bâtiments de l'âge du Fer en HauteNormandie ", in Marion S. et Blancquaert G. (éd.), Les installations agricoles de l'Âge du Fer en France septentrionale. Colloque de l'école normale supérieure, 1997. éd. Rue d'Ulm/ Presses de l'École normale supérieure, Paris, p. 321-338.

Demoule J.-P., Desenne S. et Gransar F., 2009 - "Le faciès céramique ancien de la culture Aisne-Marne ", in Chaume B. (dir.). La céramique hallstattienne : approches typologiques et chrono-culturelle. Actes du colloque international de Dijon, 21-22 novembre 2006, Dijon, Éditions universitaires de Dijon, p. 401-426.

Devals C. (dir.), 2010 - Nantes. ZAC Erdre-Porterie. Rapport Final d'Opération de fouille archéologique préventive, Nantes, ArchéoLoire - SRA Pays de la Loire, 3 vol.

Еснт R., 1999 - «Das Fürstinnengrab von Reinheim », Studien zur Kulturgeschichte der Früh-La-Tène-Zeit, Band 69 der Saarbrücker Beitrage zur Altertumskunde, Bonn, 358 p.

Forré P. (dir.), 2008 - Commune de Thouaré-sur-Loire, ZAC des Deux Ruisseaux, tranche 1 (Loire-Atlantique), Rapport Final d'Opération de diagnostic archéologique, Nantes, INRAPSRA Pays de la Loire, 49 p.
Foucault A. et Raoult J.-F., 2005 - Dictionnaire de géologie, Masson, Paris, $\sigma^{\mathrm{e}}$ édition, $382 \mathrm{p}$.

Gomez de Soto J., Lejars T., Ducongé S., Robin K., Sireix C. et ZÉlie B., 2007 - «Du milieu du v ${ }^{\mathrm{e}}$ au III ${ }^{\mathrm{e}}$ siècle av. n. è. en Centre-Ouest, Aquitaine septentrionale et ouest du Massif Central ", in Mennessier-Jounnnet C., Adam A.-M. et Milcent P.-Y. (dir.). La Gaule dans son contexte européen aux iv et iii siècles avant notre ère, Actes du XXVII ${ }^{e}$ colloque de l'AFEAF, Clermont-Ferrand, 2003. Association pour le Développement de l'Archéologie en Languedoc-Roussillon, Lattes, p. 69-89.

Guérin F. (dir.), 2003 - La Chaize-le-Vicomte, La Chapellière (Vendée). Autoroute A87. Rapport Final d'Opération de fouille archéologique, Nantes, AFAN - SRA Pays de la Loire, 180 p.

HAGEN W., 1937 - Kaiserzeitliche Gagararbeiten aus dem Rheinischen Germanien. Inaugural Dissertation, Universität zu Bonn, Darmstadt, 145 p.

Hatt J.-J. et Roualet P., 1981 - « Le cimetière des Jogasses en Champagne et les origines de la civilisation de La Tène. Deuxième partie ", Revue Archéologique de l'Est, tome 32, p. 17-63.

Hervé-Monteil M.-L., avec la coll. de Arthuis R., 2009 Mauves-sur-Loire (Loire-Atlantique), Rue de la Prime. Rapport Final d'Opération de diagnostic archéologique, Nantes, INRAP-SRA Pays de la Loire, 39 p.

Hervé-Monteil M.-L., avec la coll. de Le Guévellou R. et Nauleau J.-F., 2015 - Carquefou (Loire-Atlantique), ZAC de La Fleuriaye 2, Les Petites Renaudières : Enclos et parcellaires. Rapport Final d'Opération de fouille archéologique préventive, Nantes, INRAP-SRA Pays de la Loire, 266 p.

Jemin R. (dir.), 2016 - Carquefou (Loire-Atlantique), ZAC de la Haute Forêt - tranche 3 : une ferme gauloise à Cufroid. Rapport Final d'Opération de fouille archéologique préventive, Nantes, INRAP-SRA Pays de la Loire, 284 p.

Lallemand D. et Tuffreau-Libre M., 2005 - " La céramique 'type Besançon' en Gaule Centrale ", SFECAG, Actes du Congrès de Blois, p. 63-81.

Lамвот B., 2002 - "Maisons et société à Acy-Romance (Ardennes) ", in Méniel P. et Lambot B. (coord.). Découvertes récentes de l'âge du Fer dans le massif des Ardennes et ses marges. Repas des vivants et nourriture pour les morts en Gaule. Actes du XXXV colloque de l'AFEAF, Charlevilles-Mézières, 2001. Bulletin de la Société Archéologique de Picardie, Mémoire n 16, sup. au Bulletin n ${ }^{\circ}$ 1, p. 115-124.

Landreau G., avec la coll. de Zélie B., Bardot X., Houdusse B., Maratier B., Hess S. et Rousseau J., 2009 - « Entre isthme gaulois et Océan, la Saintonge au second Âge du Fer. État des connaissances ", in Bertrand I., Duval A., Gomez de Soto J. et Maguer P. (dir.). Les Gaulois entre Loire et Dordogne, Actes du XXXI ${ }^{e}$ colloque de l'AFEAF, Chauvigny, 2007. Mémoires de l'APC, XXXIV, p. 245-306. 
Le Gofr E., 1998 - Carquefou. Le Clouët (Les Mazères), Rapport de fouille archéologique, Nantes, AFAN-SRA Pays de la Loire, $138 \mathrm{p}$.

Le Goff E., 1999 - Chanzeaux : La Morinière, Document Final de Synthèse de Prospection, Nantes, AFAN-SRA Pays de la Loire, 12 p.

Le Goff E., 2003 - " "Armorique” et "Bretagne” : réflexion sur l'assimilation de ces concepts pour la fin de l'âge du Fer ", in Mandy B. et de Saulce A. (dir.). Les Marges de l'Armorique à l'Âge du Fer. Archéologie et Histoire: culture matérielle et sources écrites, Actes du XXIII colloque de l'AFEAF, Nantes, 1999, Revue Archéologique de l'Ouest, sup. 10, p. 103-117.

LE Goff E., 2009 - « Habitats, terroir et paysage rural : aménagement et structuration du territoire et de la campagne gauloise. Ifs, ZAC 'Object'Ifs Sud' (Calvados) ", in Bertrand I., Duval, A., Gomez de Soto J. et Maguer P. (dir.). Habitats et paysages ruraux en Gaule et regards sur d'autres régions du monde celtique. Actes du XXXI colloque de l'AFEAF, Chauvigny, 2007. Mémoires de l'APC, XXXIV, p. 93-107.

Lemaître S. et Sanchez C., avec la coll. de Arqué M.-C., Audé V., Landreau G., Maratier B. et Sireix C., 2009 "Importations italiques dans le Centre-Ouest de la Gaule à l'époque laténienne ", in Bertrand I., Duval A., Gomez de Soto J. et Maguer P. (dir.). Les Gaulois entre Loire et Dordogne. Actes du XXXI ${ }^{\text {e }}$ colloque de l'AFEAF, Chauvigny, 2007. Mémoires de l'APC, XXXIV, p. 341-370.

Levillayer A., 2006 - "L'occupation de l'âge du Fer des Chaloignes à Mozé-sur-Louet (Maine-et-Loire) ", Revue Archéologique de l'Ouest, 23, p. 117-135.

Levillayer A., avec la coll. de Le Gouestre D., 2007 - Le site du Moulin des Courtes aux Moutiers-en-Retz (44), Rapport d'étude de fouille de sauvetage, Nantes, Université de Rennes 1-SRA Pays de la Loire, $32 \mathrm{p}$.

Levillayer A., 2013 - "L'âge du Fer ", in Croix A. (dir.), Dictionnaire de Nantes, Rennes, Presses Universitaires de Rennes, p. 153.

Levillayer A., avec la coll. de du Gardin C., sous presse - «Le site de l'âge du Fer des Herbiers dans son cadre régional : qui étaient les Gaulois du Bocage?", Recherches Vendéennes.

Levillayer A., en préparation - Pornic (Loire-Atlantique), ZAC du Clos du Bocage, Le Fief-Clément. 3000 ans d'occupation à Sainte-Marie-sur-Mer, Rapport Final d'Opération de fouille archéologique préventive.

Levillayer A. et Prigent D., 2010 - «Un site de La Tène au cœur des Mauges : le Pinier à Beaupréau (Maine-et-Loire) ", Revue Archéologique de l'Ouest, 27, p. 73-84.

Levillayer A., Borvon A. et Hunot J.-Y., 2013 - « Du Hallstatt final à La Tène ancienne en Anjou : les batteries de structures de stockage de Luigné et de Cizay-la-Madeleine (Maine-etLoire) ", Revue Archéologique de l'Ouest, 30, p. 113-142.
Loughton M.-E., 2000 - La morphologie des amphores républicaines en Auvergne. SFECAG, Actes du Congrès de Libourne, p. 243-256.

Maguer P. (dir.), 2000 - Cholet : "Les Natteries ", Document Final de Synthèse de Fouilles, Nantes, AFAN - SRA Pays de la Loire, $346 \mathrm{p}$.

Maguer P., 2005 - «L'architecture des bâtiments de La Tène dans le sud du Maine-et-Loire et en Vendée : études de cas ", in Buchsenschutz O. et Mordant C. (dir.). Architectures protohistoriques en Europe occidentale du Néolithique final à l'âge du Fer. Actes des congrès nationaux des sociétés historiques et scientifiques, $127^{\mathrm{e}}$ congrès, Nancy, $15-20$ avril 2002, Paris, CTHS, p. 331-345.

Maguer P., 2007 - « Le mobilier céramique d'un fossé dépotoir sur le site des Natteries (Cholet, Puy-Saint-Bonnet, Maineet-Loire) ", in Duval A. et Gomez de Soto J. (dir.), Sites et mobiliers de l'Âge du Fer entre Loire et Dordogne, Chauvigny, Mémoires de l'APC, XXIX, p. 73-77.

Maguer P., Artuis R. et Hiernard J., avec la coll. de Hostein H. et Richard J.-M., 2005 - "L'établissement rural de la Chapellière à la Chaize-le-Vicomte (Vendée) : une ferme gauloise de la fin du deuxième âge du Fer ( $\mathrm{II}^{\mathrm{e}}$ siècle- $\mathrm{I}^{\mathrm{er}}$ siècle $\mathrm{a}$. C.) ", Aquitania, XXI, p. 21-72.

Maguer P., Landreau G., Dupont C., Martin H., Bardot X., Pouponnot G., Briand D. et Duval A., 2009a - « L'habitat littoral des Ormeaux à Angoulins (Charente-Maritime). Activités vivrières et salicoles entre marais et océan ", in Bertrand I., A. Duval, Gomez de Soto J. et Maguer P. (dir.). Les Gaulois entre Loire et Dordogne, Actes du XXXI ${ }^{\mathrm{e}}$ colloque de l'AFEAF, Chauvigny, 2007. Mémoires de l'APC, XXXIV, p. 57-102.

Maguer P., Lusson D. et Troubady M., 2009b - "Fermes, hameaux et résidences aristocratiques entre Loire et Dordogne ", in Bertrand I., Duval A., Gomez de Soto J. et Maguer P. (dir.). Les Gaulois entre Loire et Dordogne. Actes du XXXI ${ }^{e}$ colloque de l'AFEAF, Chauvigny, 2007. Mémoires de l'APC, XXXIV, p. 423-459.

Maguer P. et Robert G., 2013 - «La maison gauloise dans l'ouest et le ventre de la France ", in Krausz S., Colin A., Gruel K., Ralston I. et Dechezleprêtre T. (dir.), L'âge du Fer en Europe. Mélanges offerts à Olivier Buchsenschutz. Ausonius, Bordeaux, p. 247-258.

Malrain F., Matterne V. et Méniel P., 2002 - Les paysans gaulois, Paris, Errance, 236 p.

Malrain F. et Blancquaert G., avec la coll. de Lorho T., 2009 "Un enclos = une ferme? ", in Bertrand I., Duval A., Gomez de Soto J. et Maguer P. (dir.). Habitats et paysages ruraux en Gaule et regards sur d'autres régions du monde celtique. Actes du $\mathrm{XXXI}^{\mathrm{e}}$ colloque de l'AFEAF, Chauvigny, 2007. Mémoires de l'APC, XXXIV, p. 25-43. 
Malrain F., BlancQuaert G. et Lorho T., 2013 - L'habitat rural du second âge du Fer. Rythmes de création et d'abandon au nord de la Loire, Paris, CNRS éditions/INRAP, 264 p.

Marion S., 2004 - Recherches sur l'àge du Fer en Île-de-France. Entre Hallstatt final et La Tène finale. Analyse des sites fouillés. Chronologie et société, BAR International Series 1231, Oxford, 2 vol.

Marshall C. E., 1975 - "The jet age ", The Australian Gemmologist, 12, p. 42-55.

Maza G., 1998 - «Recherche méthodologique sur les amphores gréco-italiques et Dressel $1 \mathrm{~A}$ découvertes à Lyon ", SFECAG, Actes du Colloque d'Istres, p. 11-29.

Menez Y., 1996 - Une ferme de l'Armorique gauloise : le Boisanne à Plouër-sur-Rance (Côtes-d'Armor), Paris, Éditions de la Maison des sciences de l'Homme, 272 p. (DAF n ${ }^{\circ} 58$ )

Menez Y., 2008 - Le camp de Saint-Symphorien à Paule (Côtesd'Armor) et les résidences de l'aristocratie du second âge du Fer en France septentrionale, Thèse de Doctorat, Université de Paris 1, France, 2 vol.

Monteil M., Maligorne Y., Aubin G., Besombes P.-A., Bouvet J.-P., Guitton D., Levillayer A., Mortreau M., Thébaud S. et SAGET Y., 2009 - « Le sanctuaire gallo-romain de Vieille-Cour à Mauves-sur-Loire (Loire-Atlantique) : un bilan des connaissances ", Revue Archéologique de lOuest, 26, p. 153-188.

Munos S. (dir.), 2014 - Nantes. 41 rue de Port-la-Blanche - château du Bois Hue, Rapport final d'opération de fouille archéologique préventive, Nantes, Archeodunum - SRA Pays de la Loire, 3 vol.

Nauleau J.-F., 2009 - Nantes "ZAC Erdre-Porterie », Tranche 2, Rapport Final d'Opération de diagnostic archéologique. Nantes, INRAP - SRA Pays de la Loire, 145 p.

Nauleau J.-F., avec la coll. de Le Boulaire A. et Le GuÉvellou R., 2010 - Sainte-Luce-sur-Loire (Loire-Atlantique), Zac de la Maison Neuve 2, phase 2 : des occupations gauloises, galloromaine et moderne, Rapport Final d'Opération de diagnostic archéologique, Nantes, INRAP-SRA Pays de la Loire, 143 p.

Nillesse O., 2003 - «Les établissements ruraux gaulois de Marcé (Maine-et-Loire) et la hiérarchisation des aedificia ", in MANDY B. et DE SAulce A. (dir.), Les Marges de l'Armorique à l'Âge du Fer. Archéologie et Histoire: culture matérielle et sources écrites, Actes du XXIII colloque de l'AFEAF, Nantes, 1999, Revue Archéologique de l'Ouest, sup. 10, p. 149-172.

Nillesse O., 2004 - "Le fourreau d'épée à décor d'appliques de la Reculière (Maine-et-Loire) et son contexte ", Antiquités nationales, tome 36, p. 215-228.

Nillesse O. (dir.), 2005 - L'établissement rural de la fin de l'âge du Fer des Ecobuts à La Bruffière, Rapport Final d'Opération de fouille archéologique préventive, Nantes, INRAP-SRA Pays de la Loire, n. p.

Ouguerrram A., 2002 - Étude palynologique de la vallée de l'Erdre (affluent de la Loire, Massif armoricain, France) de la fin du
Tardiglaciaire aux époques actuelles, Nantes, Groupe d'Étude des Milieux Naturels, $121 \mathrm{p}$.

Ouguerram A. et Visset L., 2001 - « Histoire de la végétation et première mise en évidence d'un milieu marin pendant l'Holocène dans la vallée de l'Erdre et le val de Gesvres (Bassin versant de la Loire, Massif armoricain, France) ", Quaternaire, 12 (3), p. 189-199.

Pautreau J.-P., 2007 - « L'enclos funéraire protohistorique IV-V de la nécropole du Coteau de Montigné à Coulon (DeuxSèvres) ", in Duval A. et Gomez de Soto J. (dir.), Sites et mobiliers de l'Âge du Fer entre Loire et Dordogne, Chauvigny, Mémoires de l'APC, XXIX, p. 48-52.

PÉtorin N. (dir.), 2001 - La Verrie : "La Sangle 1 ", Document Final de Synthèse de Fouilles, Nantes, AFAN-SRA Pays de la Loire, 50 p.

Pétorin N. (dir.), 2009 - Ancenis. La Savinière 1-2, Rapport Final d'Opération de fouille archéologique préventive, Nantes, INRAP - SRA Pays de la Loire, 98 p.

PÉTORIN N., 2010 - Angers " Beauséjour ", un établissement rural de La Tène finale, Journées archéologiques régionales des Pays de la Loire (Angers, 25-26 novembre 2010), p. 14.

Pithon M. (dir.), 1999 - Trémentines, "Richebourg ", Document Final de Synthèse de Fouilles, Nantes, AFAN-SRA Pays de la Loire, 68 p.

Poux M., 1998 - «Les amphores et la chronologie des sites bâlois (Bâle-Gasfabrik - Bâle-Münsterhügel). Nouvelles données ", in Tuffreau-Libre M. et Jacques A. (éd.) - La céramique précoce en Gaule Belgique et dans les régions voisines : de la poterie gauloise à la céramique gallo-romaine, Actes de la table ronde d'Arras, 1996. Nord-Ouest archéologie, 9, p. 385-416.

Prêtre K. (dir.), 2014 - Saint-Herblain (Loire-Atlantique), Bagatelle/Les Thébaudières, Tranche 2, Rapport Final d'Opération de fouille archéologique préventive, Nantes, INRAP-SRA Pays de la Loire, 265 p.

Rémy J., avec la coll. de Levillayer A. et Thébaud S., 2013 - La fortification de Bouguenais "Le Taillis de la Sangle " (LoireAtlantique), Rapport Final d'Opération de prospection thématique avec sondage, Nantes, SRA des Pays de la Loire, 52 p.

RÉmy J., Routhiau M., et Nicolas T., 2016 - «L'éperon barré de la Sangle dans l'estuaire de la Loire (Bouguenais, LoireAtlantique). Prospections et fouilles : un premier bilan des acquis ", Revue Archéologique de l'Ouest, n 33, p. 139-162.

Routhiau M., avec la coll. de Levillayer A., 2016 - Le promontoire de "La Sangle ", Bouguenais, Loire-Atlantique. Rapport Final d'Opération de sondages manuels, Nantes, SRA Pays de la Loire, 76 p.

SÉlÈQue J. (dir.), 2012a - Rezé (44). ZAC de La Brosse - La Forêt 3. Rapport Final d'Opération de fouille préventive, Nantes, ArchéoLoire - SRA Pays de la Loire, 3 vol. 
SÉLÈque J. (dir.), 2012b - Savenay, ZAC de la Colleraye, Rapport Final d'Opération de fouille archéologique préventive, Nantes, ArchéoLoire - SRA Pays de la Loire, 2 vol.

Tessier M., 1980 - Les occupations humaines successives de la zone côtière du Pays-de-Retz, des temps préhistoriques à l'époque mérovingienne, Thèse d'État, Université de Tours, France, 375 p.

Tessier M., 2003 - « Du Bronze final à l'âge du Fer dans l'estuaire de la Loire ", Bulletin du Groupe Vendéen d'Études Préhistoriques, no 39, p. 34-48.

Toledo I Mur A. et Pernot M., 2008 - «Un atelier monétaire gaulois près de Poitiers ", Gallia, t. 65, p. 231-272.

Toron S. (dir.), 2016 - Aigrefeuille-sur-Maine (Loire-Atlantique), Les Ténauderies. Un établissement rural gaulois au sud de la Loire, Rapport Final d'Opération de fouille archéologique préventive, Nantes, Eveha-SRA Pays de la Loire, 724 p.

Tyers P., 2001 - «Camulodunum type 262. Central Gaulish coarse wares in Iron Age Britain ", in Tuffreau-Libre M. et JaCQues A. (dir.), La céramique en Gaule et en Bretagne romaines: commerce, contacts et romanisation, Actes de la table ronde d'Arras, 1998. Nord-Ouest Archéologie, no 12, p. 87-106.

VACHer S. (dir.), 1992. - Rapport de sauvetage programmé du site 44026001 AH, La Bréchetière, commune de Carquefou (LoireAtlantique), Nantes, AFAN - SRA Pays de la Loire, 22 p.

VAcher S. (dir.), 2000 - Déviation de Pied-Pain - La Gravouillerie (RD 117), Document Final de Synthèse de Fouille, AFANSRA Pays de la Loire, 22 p.
VAlais A. (dir.), 2012 - Carquefou (Loire-Atlantique), ZAC de la Haute Forêt, tranche 2, Rapport Final d'Opération de fouille archéologique préventive, Nantes, INRAP-SRA Pays de la Loire, $479 \mathrm{p}$.

VIAU Y. (dir.), 2008 - La Civerda, Le Bignon (Loire Atlantique), Rapport Final d'Opération de fouille archéologique préventive, Nantes, INRAP-SRA Pays de la Loire, 220 p.

VIAu Y. (dir.), 2010 - Ancenis, ZAC de la Savinière zone 5. Un village ligérien du Bronze à La Tène, Rapport Final d'Opération de fouille archéologique préventive, Nantes, INRAP-SRA Pays de la Loire, 2 vol.

VIau Y. (dir.), 2014 - ZAC de Toutes Joies II (Pays de la Loire, Loire-Atlantique, Gétigné), Rapport Final d'Opération de fouille archéologique préventive, Nantes, INRAP-SRA Pays de la Loire, $338 \mathrm{p}$.

WATTS S., 1996 - The geochemical charaterisation of jet and jet-like objects in archaeology. A discussion of analytical methods for the identification of archaeological black lithic materials, with a case study of objects from Roman York and Verulamium, Thèse de doctorat, University of Bradford, 2 vol.

Weller M. et Wert C., 1993 - "The fossil hydrocarbon jet: Historische, physikalische und materialkundliche aspekte des fossilen Kohlenwasserstoffs Gagat ", Die Geowissenschaften (Weinheim, Zeitschrift), 9, p. 319-325.

Zusammenfassung: Der Fundplatz von Bois Hue in Nantes (Loire-Atlantique) und die jüngere Eisenzeit im Zwischenstromgebiet von Erdre und Loire - Die erste archäologische Ausgrabung einer Siedlung der jüngeren Eisenzeit in Nantes (Loire-Atlantique, Frankreich) hat einige spezifische Besonderheiten hervorgebracht. Dazu gehören u.a. die lange Besiedlungsdauer, die vom Ende des 4. Jh. v. Chr. bis zum 1. Jh. v. Chr. reicht, ein breiter Graben sowie ein umfangreiches archäologisches Fundmaterial. Das archäologische Umfeld des Fundplatzes ist ebenfalls bemerkenswert, da die Siedlung von Le Bois Hue im Gebiet zwischen den Flüssen Erdre und Loire liegt, einer Kleinregion, in der die jüngsten Maßnahmen der Rettungsarchäologie eine dichte eisenzeitliche Besiedlung belegen konnten. Berücksichtigt man diese neuen Erkenntnisse und ihre Hintergründe und Zusammenhänge, so gestatten die hier vorgestellten Grabungsergebnisse, eine erste Bilanz der jüngereisenzeitlichen Besiedlung im Gebiet von Nantes zu ziehen.

Resumen: El yacimiento del Bois Hue en Nantes (Loire-Atlantique) y la Segunda Edad del Hierro en el interfluvio Erdre-Loira-La primera excavación de un yacimiento galo en Nantes pone de relieve su particularidad, que se manifiesta por una ocupación larga desde el final del s. IV hasta el s. I a. n. e., la presencia de un enorme foso y de material abundante. Su entorno arqueológico presenta el mismo interés, ya que el yacimiento del Bois Hue se enmarca dentro de un territorio especifico, el de la confluencia entre el Erdre y el Loira, que las intervenciones de arqueología preventiva han revelado como un espacio densamente ocupado en la Edad del Hierro. En este marco, la excavación aqui presentada permite establecer un primer balance de la ocupación gala de Nantes.

Schlüsselwörter: Latènezeit, umhegtes Gehöft, Siedlungsstruktur aus Gehöftanlagen, Gebäude, Keramik, Amphoren, Lignit, Mahlsteine, Handelsbeziehungen.

Palabras clave: La Tène, recintos, conjunto de poblados, arquitectura, cerámica, ánforas, azabache, molinos, intercambios comerciales. 